\title{
The effect of omega-3 enhanced fish consumption on C-reactive protein levels in post-menopausal women
}

\author{
Megan Moran \\ West Virginia University
}

Follow this and additional works at: https://researchrepository.wvu.edu/etd

\section{Recommended Citation}

Moran, Megan, "The effect of omega-3 enhanced fish consumption on C-reactive protein levels in postmenopausal women" (2010). Graduate Theses, Dissertations, and Problem Reports. 2968.

https://researchrepository.wvu.edu/etd/2968

This Thesis is protected by copyright and/or related rights. It has been brought to you by the The Research Repository @ WVU with permission from the rights-holder(s). You are free to use this Thesis in any way that is permitted by the copyright and related rights legislation that applies to your use. For other uses you must obtain permission from the rights-holder(s) directly, unless additional rights are indicated by a Creative Commons license in the record and/ or on the work itself. This Thesis has been accepted for inclusion in WVU Graduate Theses, Dissertations, and Problem Reports collection by an authorized administrator of The Research Repository @ WVU. For more information, please contact researchrepository@mail.wvu.edu. 
The effect of omega-3 enhanced fish consumption on C-Reactive Protein levels in postmenopausal women.

\section{Megan Moran}

Thesis submitted to the Davis College of Agriculture, Natural Resources and Design

At West Virginia University

In partial fulfillment of the requirements

for the degree of

Master of Science

in

Human Nutrition and Foods

Cindy Fitch, $\mathrm{PhD}$, RD, Chair

Jacek Jaczynski, PhD

Susan Partington, PhD, RD

Ken Semmens, PhD

Morgantown, WV

2010

Keywords: C-Reactive Protein, heart disease, inflammation, omega-3 fatty acids, postmenopausal, trout 


\section{ABSTRACT \\ The effect of omega-3 enhanced fish consumption on C-Reactive Protein levels in post-menopausal women.}

\section{Megan Moran}

Heart disease is the leading killer of women in the United States, and the risk is 2-3 times greater in post-menopausal than pre-menopausal women. C-Reactive protein (CRP) is an inflammatory marker that has been identified as a risk factor for heart disease. The objective of this study was to determine if increased consumption of omega-3 fatty acids, known for their anti-inflammatory properties, reduced CRP levels in post-menopausal women. A sample of 29 women was recruited to participate in the study. Participants were randomly assigned to two groups, experimental and control. The women were instructed to follow a heart healthy diet for eight weeks and to avoid all fish, seafood, and omega-3 enhanced products for the duration of the study (8 weeks). In addition to the heart healthy diet and restricted omega-3 guidelines, subjects in the experimental group were provided two 4 ounce servings of omega- 3 enhanced trout each week. The control group subjects were instructed on the same diet guidelines but were not given the omega3 enhanced trout. Seven day food diaries were recorded and blood tests were performed to determine CRP, interleukin-6 (IL-6), total cholesterol, HDL cholesterol, LDL cholesterol, VLDL cholesterol and triglyceride levels at the beginning and end of the study. No significant pre- to post-study changes between groups were seen for CRP $(p=0.34)$, total cholesterol $(p=0.64)$, HDL cholesterol $(p=0.65)$, LDL cholesterol $(p=0.50)$, VLDL cholesterol $(p=0.91)$ and triglycerides $(p=0.92)$. Participants in the fish group significantly increased their consumption of omega-3 fatty acids $(p=0.004)$ during the eight week study. A majority $(87.5 \%$ ) of the experimental group and $85.7 \%$ of the control group experienced no change or a decrease in CRP. A similar trend was evident for Il-6 levels. The addition of two servings of omega-3 enhanced trout per week for eight weeks was successful in increasing n-3 intake in post-menopausal women; however the increased n-3 intake did not produce significant changes in markers of inflammation over the course of the study. 


\section{ACKNOWLEDGEMENTS}

This project was funded as a USDA Hatch Project as the Aquaculture Product and Marketing Development Project (project \# WVA00477, CRIS \# 0120721).

I want to extend sincere appreciation to the members of my committee, Drs. Cindy Fitch, Jacek Jaczynski, Susan Partington and Ken Semmens for their guidance and support throughout this project. I want to thank Dr. Janet Tou for her advice and support. I am thankful to Dean Cameron Hackney for his encouragement and financial support during my tenure as a graduate student in the division of Animal and Nutritional Sciences. I am also grateful to Helenia Sedoski for her hard work and dedication to this project and to the participants who enrolled in my study.

Lastly, I want to thank my family, friends and classmates who offered their continued guidance, support and encouragement as I completed this project. 


\section{TABLE OF CONTENTS}

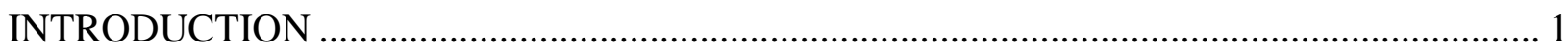

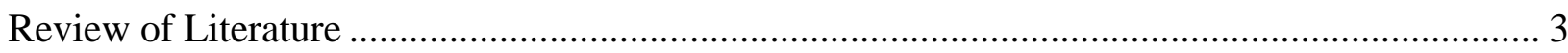

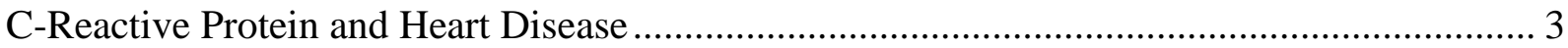

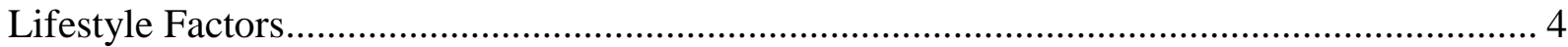

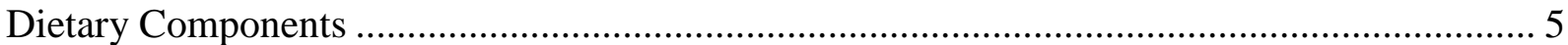

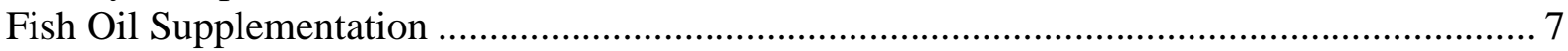

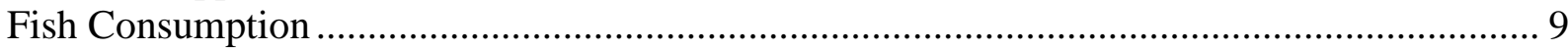

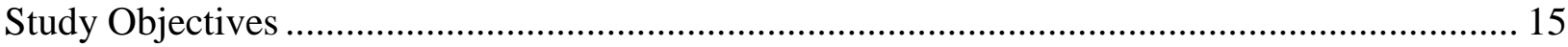

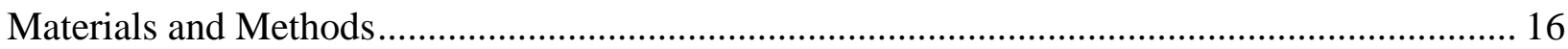

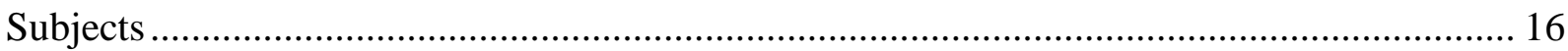

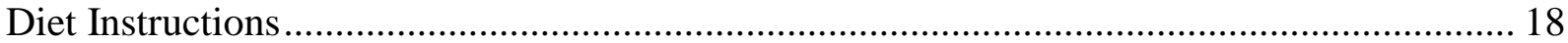

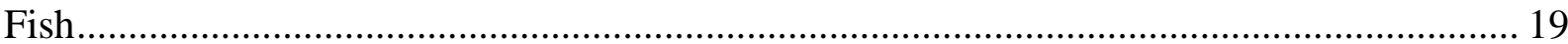

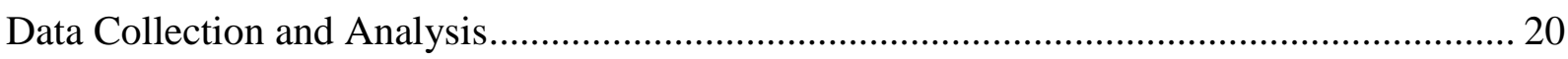

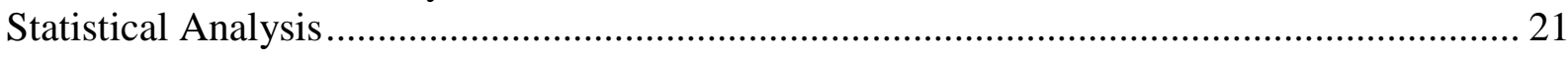

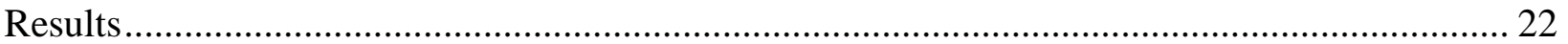

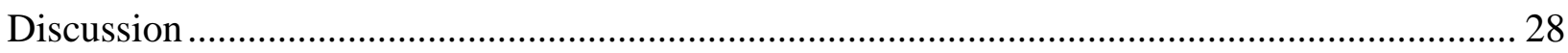

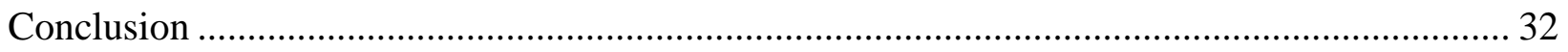

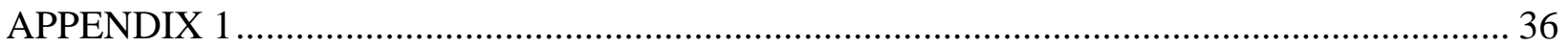

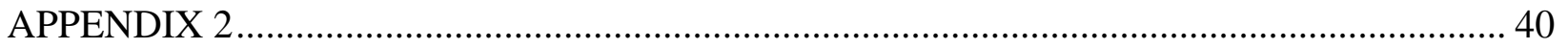




\section{LIST OF TABLES}

Table 1: 12 week schedule for fish group participants. ...................................................... 19

Table 2: Fatty Acid Composition of Brook Trout ............................................................ 20

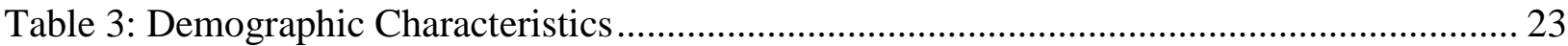

Table 4: Lifestyle Characteristics ............................................................................. 24

Table 5: Pre- and Post-Study Mean Intakes for Fat and Fiber, Within Group Comparisons ....... 25

Table 6: Mean Change in Fat and Fiber Intakes Pre- and Post-Study, between Group

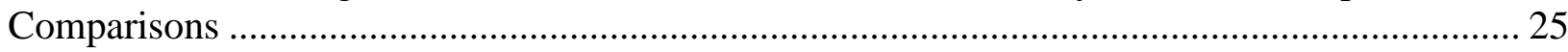

Table 7: Pre- and Post-Study Mean Lipid Levels and CRP, Between Group Comparisons ........ 26

Table 8: Mean Change in Lipid Levels, Pre- and Post-Study, Between Group

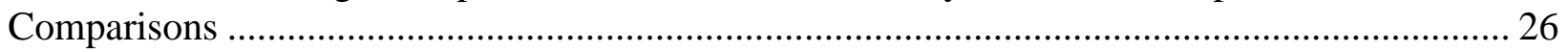

Table 9: Pre- and Post-Study Mean Lipid Levels and CRP, Within Group Comparisons ........... 26

Table 10: Proportion of Participants with Increased Lipid, CRP, and IL-6 Levels,

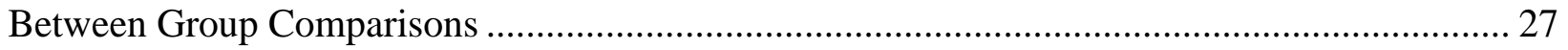




\section{INTRODUCTION}

The leading cause of death in women in the United States is coronary heart disease (CHD), with rates 2-3 times greater among post-menopausal than pre-menopausal women. ${ }^{1}$ Additionally, $64 \%$ of all women who die suddenly from CHD have had no prior symptoms of the

disease. ${ }^{2}$ Identifying additional non-traditional risk factors and methods of treatment, including both medications and lifestyle modifications, is of great interest in reducing rates of CHD.

CHD is a condition where blood vessels leading to the heart narrow, limiting the supply of blood and oxygen to the heart, putting a person at increased risk for a myocardial infarction (heart attack). ${ }^{3}$ Researchers have been investigating the role of inflammation in atherosclerosis, the process of plaque formation that leads to narrowing of the arteries. C-reactive protein (CRP) is a marker of inflammation, causing it to gain attention in recent years as a risk factor for CHD. ${ }^{4}$ Moreover, CRP has been declared a better predictor of risk for coronary events than traditional indicators, such as LDL cholesterol. ${ }^{5}$ This is especially important as LDL cholesterol and CRP values are not correlated, meaning that individuals may have low to normal LDL cholesterol but have high CRP values or vice versa. CRP is also relatively stable and inexpensive to measure. ${ }^{6}$ The lack of correlation between CRP and LDL cholesterol and ease of measuring in a clinical setting is further justification for including CRP as a screening took for CHD.

Serum CRP values between $1 \mathrm{mg} / \mathrm{L}$ and $10 \mathrm{mg} / \mathrm{L}$ are of importance in determining CHD risk. ${ }^{4}$ Serum CRP levels less than $1 \mathrm{mg} / \mathrm{L}$ indicate the patient is at low risk, $1 \mathrm{mg} / \mathrm{L}$ to $3 \mathrm{mg} / \mathrm{L}$ indicate intermediate risk and greater than $3 \mathrm{mg} / \mathrm{L}$ indicate a high risk. Individuals with CRP values greater than $10 \mathrm{mg} / \mathrm{L}$ should be retested and examined to exclude other health conditions such as infections, autoimmune diseases, or cancer that may be causing the high values. ${ }^{4}$ 
Scientists are currently interested in determining which lifestyle factors play a role in reducing CRP levels. Several studies have looked at the effects of dietary components, including fiber $^{7}$, arginine ${ }^{8}$, fruits and vegetables ${ }^{9}$ and fish $^{10}$ on levels of CRP due to their cholesterol lowering and anti-inflammatory properties. Fish and fish oil are of particular interest because of the omega-3 (n-3) fatty acids they contain. In addition, research has been done to determine the effect of exercise on levels of CRP. ${ }^{11}$ This research study will primarily focus on the effects of fish consumption on CRP levels in post-menopausal women. This document will outline the study methods, specific aims and results of the project, but first, a review of the literature will introduce the reader to current understandings of the role of CRP in CHD. 


\section{REVIEW OF LITERATURE}

\section{C-Reactive Protein and Heart Disease}

$\mathrm{C}$-reactive protein (CRP) is a protein produced in the liver that is being investigated as a predictor of future coronary events. ${ }^{12}$ CRP plays a role in atherosclerosis in several ways - it is deposited in atherosclerotic plaques, activates macrophages, aids in LDL cholesterol uptake, increases IL-6 production, and promotes inflammatory responses. ${ }^{4,13,14}$ CRP has been found to be positively correlated with BMI, triglycerides, fasting glucose, and blood pressure and negatively correlated with HDL cholesterol levels, all of which are indicators for risk of future coronary events. ${ }^{15-17}$

Several studies have found a positive relationship between increased CRP and risk for future coronary events. ${ }^{12,15,18}$ In a three year study involving 28,263 healthy post-menopausal women from the Women's Health Study, high sensitivity CRP (hsCRP) was found to be a strong predictor of future coronary events (death from CHD, nonfatal MI or stroke, or coronaryrevascularization procedures). ${ }^{12}$ When comparing baseline levels of several inflammatory markers including CRP, interleukin-6 (IL-6), serum amyloid A (SAA) and soluble intercellular adhesion molecule type 1 (sICAM-1), CRP was most strongly associated with risk of coronary events. In a univariate analysis, a relative risk of 4.4 (95\% CI: 2.2 to $8.9, \mathrm{P}<0.001)$ was noted for women in the highest quartile of CRP versus the lowest quartile. The relative risk for postmenopausal women with "low-risk" values for LDL cholesterol (below $130 \mathrm{mg} / \mathrm{dL}$ ), but in the highest quartile of CRP, was 3.1 (95\%CI: 1.1 to $8.3, p=0.03$ ).

Similar results were seen in a population of 9,758 men ages 50-59 years old followed for

a period of 5 years in the PRIME study. ${ }^{15}$ At baseline, all participants were free of heart disease. CRP was found to be significantly correlated with increased risk for CHD events, specifically 
nonfatal MI and coronary death $(p=0.01)$. The relative risk for patients with CRP values in the highest tertile versus the lowest tertile was 1.92 (95\%CI: 1.14-3.22). Concurring results were seen by Danesh, et al. ${ }^{18}$ in the Reykjavik Study regarding the role of CRP in predicting the risk of CHD. The study population consisted of 2,459 men and women who experienced a nonfatal MI or death from CHD and 3,969 control subjects. The odds ratio for CHD risk was 1.45 (95\%CI: 1.25-1.68) when comparing the baseline CRP values for the highest third of the population of the study to the lowest third after adjustment for confounding factors. An updated meta-analysis performed by the researchers concluded an odds ratio of 1.49 (95\% CI: 1.37 to 1.62, $p=0.01$ ) for patients in the highest tertile versus lowest tertile of baseline CRP values. This is less than the odds ratio of 2.0 (95\% CI: 1.6 to 2.5$)$ that Danesh, et al. reported in a prior metaanalysis. $^{19}$

\section{Lifestyle Factors}

With the emerging evidence that elevated CRP is correlated with an increased risk of heart disease, researchers are interested in finding lifestyle factors, such as physical activity and dietary components, that can affect CRP levels. Colbert ${ }^{11}$ investigated the effect of exercise and non-exercise (i.e. housework, gardening) physical activity on CRP levels in a population of black and white men and women between the ages of 70-79 years. The researchers determined that CRP levels were lower for those reporting higher amounts of physical activity and non-exercise physical activity after adjustment for confounding factors, such as age, sex, race and diseases associated with inflammation $(p=0.018)$. The researchers concluded that increased physical activity, in the form of exercise and non-exercise activity, is associated with lower levels of CRP.

Mora, et $\mathrm{al}^{20}$ aimed to quantify which traditional and non-traditional risk factors were affected the most by physical activity, thus contributing the most to the reduced risk for 
cardiovascular events associated with increased physical activity. In this study, the researchers assessed participants for CHD, a form of cardiovascular disease (CVD). CVD also includes cardiovascular events such as nonfatal myocardial infarction and nonfatal ischemic stroke. Participants were a subset of 27,055 apparently healthy women from the Women's Health Study. Baselines measurements were obtained for traditional risk factors for CVD including lipids, weight, height and hypertension, and non-traditional risk factors such as CRP, fibrinogen and soluble intercellular adhesion molecule-1 (sICAM-1). Follow up surveys assessing for cardiovascular events including CHD and nonfatal MI were completed by participants every 6 or 12 months. It was determined that inflammatory/hemostatic biomarkers, such as hsCRP, have a significant involvement in the physical activity associated risk reduction for CHD $(p=0.01)$ but not CVD risk $(p=0.1)$. The researchers concluded that $59 \%$ of the reduction in CVD rates and $35.5 \%$ of the reduction in CHD rates that is associated with increased physical activity can be explained by the traditional and non-traditional risk factors investigated in this study. The inflammatory and hemostatic biomarkers investigated (hsCRP, fibrinogen and sICAM-1) were found to be the most influential in explaining the reduced risk of CVD and CHD associated with increased physical activity. The change in inflammatory and hemostatic biomarkers explained $32.6 \%$ of the reduction in CVD risk and 20.9\% of the reduction in CHD risk seen with increased physical activity.

\section{Dietary Components}

In addition to physical activity, dietary components may influence levels of CRP. Dietary arginine $^{8}$, fiber ${ }^{9}$, cherries ${ }^{21}$, strawberries ${ }^{22}$ and omega-3 fatty acids ${ }^{9}$ have been linked to reduced levels of CRP. Arginine, a component of nuts and fish, has been investigated due to its reported antioxidant and anti-inflammatory properties. ${ }^{8}$ Data from the NHANES III study showed that participants who consumed the highest amount of arginine, compared to those with median 
consumption, were $30 \%$ less likely to have CRP values above $3.0 \mathrm{mg} / \mathrm{L}$. Additionally, those who consumed the lowest amounts of arginine were more likely to have increased levels of CRP $(\mathrm{P}<0.05)$.

Consumption of fruits and vegetables is another potential dietary factor in decreasing CRP levels due to the anti-inflammatory properties of their antioxidant components. ${ }^{9}$ Cherries are rich in antioxidants, including anthocyanins, which have been shown to reduce inflammation. ${ }^{21}$ A study of 10 healthy women between the ages of 22 and 40 years old showed a decrease in CRP levels 3 hours after consumption of Bing sweet cherries $(\mathrm{P}<0.1)$, however no decrease was noted 5 hours after consumption. Strawberries also have a potential role in reducing the risk for CVD. ${ }^{22}$ Strawberries are a rich source of flavonoids, fiber, folate, vitamin C and potassium, which contribute to their potential heart healthy effects. Sesso, et al. ${ }^{22}$ noted no significant relationship between low strawberry consumption (rarely/never) and CVD risk among a subset of the participants in the Women's Health Study. However, a borderline significant association for reduced CRP values was seen in women with increasing strawberry consumption ( $\mathrm{p}$ for trend $=0.012$ ).

Fiber, which is found in fruits and vegetables as well as whole grains, has also been shown to play a role in reducing CRP levels. ${ }^{7,9}$ Twenty eight women and 7 men were randomly assigned a diet containing $30 \mathrm{~g} / \mathrm{d}$ of fiber from high fiber foods or a fiber supplement. ${ }^{7}$ Participants were either lean, non-hypertensive $(n=18)$ or obese hypertensive $(n=17)$ with a mean age of $38.3+/-1.2$ years. In lean participants, CRP levels decreased by $30 \%(\mathrm{P}<0.05)$ and $40 \%$ $(\mathrm{P}<0.05)$ in the high-fiber and fiber supplemented groups, respectively. A decrease was seen in obese patients; however the changes were not significant. 
There have been mixed results presented on the relationship of CRP levels to total fat, saturated fatty acids, monounsaturated fatty acids and polyunsaturated fatty acids. ${ }^{23,24}$ While the mechanism remains unclear, a strong association has been made between increased intake of n-3 fatty acids and a lower risk of cardiac events. ${ }^{25}$ One proposed mechanism involves competitive inhibition between arachadonic acid (ARA), an omega-6 fatty acid, and docosahexaenoic acid (DHA) and eicosapentaenoic acid (EPA), two long-chain omega-3 fatty acids. ARA is a substrate for proinflammatory eicosanoids which play a role in atherogenesis. EPA and DHA can displace ARA in cell membranes, thus making it unavailable for eicosanoid production. ${ }^{26}$ The eicosanoids produced by the n-3 fatty acids are much less reactive than those produced by ARA, and reduce inflammation, vasoconstriction and platelet aggregation. ${ }^{25}$ In addition to decreasing proinflammatory eicosanoid production, EPA and DHA impair production of proinflammatory cytokines, such as interleukin-6 (IL-6) and tumor necrosis factor alpha. ${ }^{27}$ While many cytokines can play a role in hepatic CRP synthesis, IL- 6 is the primary mediator. ${ }^{28}$ DHA and EPA can be made in the body by the conversion of the omega-3 fatty acid alpha-linolenic acid (ALA), however this conversion is very inefficient. ${ }^{29}$ It is estimated that less than $5 \%$ of the ALA consumed is converted to DHA and EPA.

\section{Fish Oil Supplementation}

Fatty fish are an excellent source of DHA and EPA. Thus there is an interest in determining if a relationship between fish oil supplementation or fatty fish consumption and decreased CRP exists. The effect of fish oil supplements on CRP levels was examined in men and women between the ages of 50 and 70 years old. ${ }^{30}$ This study was performed on 43 men and 41 post-menopausal women. Participants were randomly selected within strata of habitual fish consumption, diastolic blood pressure and sex to receive either a placebo or a fish oil supplement 
pill. The fish oil supplement provided a daily supplement of 3.5 grams of fish oil (1.5 g/day n-3 fatty acids): $700 \mathrm{mg}$ EPA, $560 \mathrm{mg}$ DHA and $260 \mathrm{mg}$ of other $\mathrm{n}-3$ fatty acids. The placebo contained high-oleic-acid sunflower oil. Participants were asked to avoid fish, seafood or additional fish oil supplements starting 4 weeks before the study until the end of the 12 week study. With the exception of the fish restriction, participants were to maintain their normal diet and lifestyle during the study and to record any illness, medications or changes to their normal lifestyle habits during the study. Three participants were excluded from this study due to CRP levels greater than $10 \mathrm{mg} / \mathrm{dL}$ and flu like symptoms prior to blood collection. Comparison of baseline CRP levels to CRP levels after the 12 week study revealed that median changes in CRP levels were $+0.01 \mathrm{mg} / \mathrm{dL}$ and $-0.17 \mathrm{mg} / \mathrm{dL}$ for the fish oil and placebo groups, respectively. The changes in the two groups were not significantly different $(p=0.057)$. From this, the researchers determined that supplementation with fish oil did not lower CRP levels in healthy middle-aged participants.

Similar results were seen in a population of 60 healthy volunteers ( 25 women, 35 men, mean age 38 years) given either 6.6g n-3 PUFA/day, $2.0 \mathrm{~g} \mathrm{n}-3$ PUFA/day or a placebo of $7 \mathrm{~g}$ olive oil/day. ${ }^{16}$ The high dose of PUFA contained $3.0 \mathrm{~g}$ EPA and $2.9 \mathrm{~g}$ DHA. The low PUFA dose contained $0.9 \mathrm{~g}$ EPA, 0.8g DHA. Supplements were taken for 12 weeks with blood samples obtained at baseline and after 12 weeks of supplementation. No reductions in CRP were seen after supplementation with fish oil in either group. However the researchers noted that the subjects in this study were healthy and had low baseline CRP values, so a large reduction in CRP from baseline was not expected.

More promising results with fish oil supplementation have been seen in male patients with a history of a myocardial infarction (MI). ${ }^{31}$ In a study of 40 men in a cardiac rehabilitation 
program after MI, CRP decreased in participants given a daily supplementation of DHA and EPA over a 12 month period $(\mathrm{P}<0.05)$. CRP was significantly decreased in the supplement group from a baseline value of $3.9 \mathrm{mg} / \mathrm{L}$ to $3.12,2.48$ and $2.01 \mathrm{mg} / \mathrm{L}$ at months 6,9 and 12 of the study, respectively, $(\mathrm{P}<0.05)$. Significant differences between the supplement and control groups were noted at months 6 and $12(\mathrm{P}<0.05)$. CRP levels showed a significant inverse relationship with the plasma concentration of EPA+DHA $(\mathrm{r}=-0.52, p=0.03)$ and EPA $(\mathrm{r}=-0.51, p=0.04)$. The supplement was given in the form of $500 \mathrm{~mL} /$ day skim milk containing $19 \mathrm{~g} / \mathrm{L}$ total fat, 2.1 $\mathrm{g} / 100 \mathrm{~g}$ fat of EPA, $1.2 \mathrm{~g} / 100 \mathrm{~g}$ fat of DHA, $54.4 \mathrm{~g} / 100 \mathrm{~g}$ fat of oleic acid, and $300 \mu \mathrm{g} / \mathrm{L}$ folic acid. The supplement was also fortified with vitamins A, B-6, D and E. Participants in the control group received $500 \mathrm{~mL} / \mathrm{d}$ skim milk fortified with vitamins A and D that contained undetectable amounts of EPA and DHA and $21.5 \mathrm{~g} / 100 \mathrm{~g}$ fat of oleic acid. Similar results with fish oil supplementation were also seen in hypertriglyceridemic men. ${ }^{32}$ Thirty four men between the ages of 39 and 66 years old with triglyceride values greater than $150 \mathrm{mg} / \mathrm{dL}$ were randomly assigned to a group receiving $3 \mathrm{~g} \mathrm{DHA/day} \mathrm{or} \mathrm{a} \mathrm{placebo} \mathrm{of} \mathrm{olive} \mathrm{oil} \mathrm{for} 90$ days, following an initial 8 day period of no supplementation. CRP concentrations were not significantly changed after 45 days, however a decrease of $15 \%$ was noted after 91 days $(p<0.05)$. These results suggest that supplementation with fish oil decreases CRP concentration, but that sufficient time must be given before a decrease can be seen.

\section{Fish Consumption}

Fish oil supplements are a convenient method for increasing consumption of marine derived n-3 fatty acids on a daily basis; however study results have been mixed on their ability to decrease levels of CRP. It is intuitive to question if the results would be different when DHA and EPA were consumed directly from fatty fish as opposed to a supplement that has undergone 
many processing steps and may not include all of the beneficial nutrients found in the whole food.

Fish consumption was shown to have a beneficial effect on CHD and total mortality risks in diabetic women. ${ }^{33}$ The participants in this study were a subpopulation of nurses participating in the Nurses' Health Study. Nurses between the ages of 30 and 55 (in 1976) who had reported physician diagnosed diabetes between 1976 and 1994 were included in this study. Medical histories and lifestyle information surveys were collected at baseline and every 2 years thereafter. Those who had reported any history of heart disease, stroke or cancer on or before the 1980 questionnaire were excluded from this analysis. A semiquantitative food frequency questionnaire (FFQ) was included with the follow up surveys that allowed the researchers to quantify fish and long-chain n-3 fatty acid consumption. Fish oil supplementation was not investigated in this study due to lack of participant use. An increased consumption of fish was found to be significantly associated with decreased incidence of CHD (adjusted for age; $\mathrm{p}$ for trend $=0.003$ ). Further analysis, determined the relative risk factors to be $0.70,0.60,0.65$ and 0.38 for fish consumption 1-3 times per month, once per week, 2-4 times per week and 5 or more times per week, respectively ( $\mathrm{p}$ for trend $=0.002$ ). A lower risk of fatal CHD and nonfatal myocardial infarction was significantly associated with increased fish consumption. A decreased risk for CHD was also associated with n-3 fatty acid intake, however not as strongly as with fish consumption. This discrepancy may have been due to errors in estimating the n-3 fatty acid content of fish or other components of the diet.

In the ATTICA study, researchers looked at the relationship of fish consumption on inflammatory markers, such as CRP, in individuals with no prior evidence of cardiovascular disease ${ }^{10}$ In this study of 1,514 men and 1,528 women, participants completed a food frequency 
questionnaire reporting their weekly consumption of a variety of foods over the course of the prior year. Fish consumption was ranked on a scale from none $(<150 \mathrm{~g} / \mathrm{week})$ to frequent $(>300$ g/week). Blood samples of participants after a 12 hour fast were analyzed for inflammatory markers (CRP, IL-6, serum amyloid A, TNF-alpha and white blood cell counts). Information was collected to categorize participants based on age, gender, average annual income, years of schooling, leisure time physical activity and smoking status. BMI, blood pressure and serum cholesterol levels were determined. All inflammatory markers examined were inversely related to fish consumption and to $\mathrm{n}-3$ intake. Those in the highest fish consumption category had lower levels of inflammatory markers than those who were moderate or rare consumers of fish $(\mathrm{r}=-$ $0.12, p<0.001)$. An inverse relationship between all inflammatory markers and fish consumption was still noted after adjusting for potential confounding factors. In addition, the researchers in the ATTICA study noted that a strong inverse relationship between fish $/ \mathrm{n}-3$ consumption and inflammatory markers was seen in individuals with diabetes and hypertension, but not those with hypercholesterolemia. Lastly, the researchers determined that the optimal intake of n-3 fatty acids was $0.6 \mathrm{~g}$ per day to maximize benefits.

Several studies have looked at the effect of fish consumption on CRP levels in Japanese men and women, since their intake of marine products is higher than in a typical Western diet. ${ }^{23,}$ ${ }^{24,34}$ Female Japanese dietetic students between the ages of 18 and $22(n=443)$ showed an inverse relationship between CRP and total $\mathrm{n}-3$ fatty acid intake. ${ }^{24}$ Dietary intake in this population was obtained using a diet history questionnaire (recall) for the month prior to the study and blood samples were taken after completion of the diet history. The results showed an inverse relationship between total n-3 PUFA consumption and CRP levels; however there was not a significant association between EPA+DHA intake and CRP levels $(p=0.62)$. Odds ratios for 
elevated CRP levels of 0.33 and 1.0 were determined for women consuming n-3 PUFAs in quantities above and below the median, respectively (95\% CI 0.13-0.82, $p=0.02)$.

Similar results were seen in a middle aged population of Japanese men $(n=1556)$ and women $(n=1461) .{ }^{23}$ In this study a diet history questionnaire was used to obtain dietary intake for the month prior to the study. Serum CRP was measured and values were compared to dietary intakes of the n-3 fatty acids EPA, DHA and alpha-linolenic acid; the n-6 fatty acid linoleic acid; the n-9 fatty acid oleic acid; and saturated fatty acids palmitic and stearic. There were no significant associations between increased EPA or DHA intakes and CRP values in men or women. There was a significant inverse relationship between an increased consumption of total n-3 PUFAs and CRP level in women $(\mathrm{P}$ for trend $=0.02)$ and a non-significant but similar trend seen in men $(\mathrm{P}$ for trend $=0.409)$. In participants consuming quantities of EPA+DHA in the middle tertile of the population, oleic acid and lineoleic acid in men, and oleic acid, lineoleic acid and ALA in women were inversely related to serum CRP concentrations. This result suggests that a moderate intake of EPA+DHA may influence the relationship between other fatty acids and CRP levels.

Investigating the role of fish consumption on CRP levels in an elderly Japanese population (greater than 70 years old) also showed promising results. ${ }^{34}$ In this study of 401 men and 570 women with baseline CRP values below $10 \mathrm{mg} / \mathrm{L}$, dietary intake was collected using a brief diet history questionnaire for the period of 1 year prior to the study. Low CRP was defined as values below $1.0 \mathrm{mg} / \mathrm{L}$ and high as values above or equal to $1.0 \mathrm{mg} / \mathrm{L}$. Total $\mathrm{n}-3$ PUFA intake and EPA+DHA intake were related to decreased CRP concentrations; however this was not statistically significant ( $p$ for trend $=0.051$ and 0.20 , respectively). The risk for high CRP concentrations significantly decreased with increased consumption of total n-3 PUFAs (Odds 
Ratios (OR) for increasing quartiles: 1.0, 0.72, 0.57, 0.44, P for trend $=0.01$ ) and EPA+DHA (ORs for increasing quartiles: 1.0, 0.91, 0.76 and $0.54, \mathrm{P}$ for trend $=0.03$ ). Decreasing CRP concentrations were also seen with increasing EPA consumption and DHA consumption ( $p$ for trend $=0.02$ and 0.01 , respectively). These results suggest that an increased consumption of $n-3$ fatty acids, through marine sources such as fatty fish, is associated with a decreased level of CRP.

In the only known clinical trial published to date regarding fish consumption and CRP levels, Tsitouras, et al ${ }^{35}$ investigated the effects of fatty fish and fish oil consumption in twelve relatively healthy men and women 60-75 years old. Participants consumed a control diet for 6 weeks containing four 6-ounce servings of non-fatty fish per week, no servings of fatty fish, a corn/olive oil placebo, and limited amounts of trans-fatty acids. After the control period, participants consumed a similar diet however the non-fatty fish was replaced with fatty fish and a daily fish oil supplement ( $15 \mathrm{~mL} /$ day, providing 4-5 grams of $\mathrm{n}-3$ fatty acids) was provided for the duration of 8 weeks. Blood measurements were obtained at baseline, week 6 and week 14 of the study. There was a significant decrease in the n-6 to n-3 ratio present in red blood cell membranes after the 8 week intervention diet $(p<0.0001)$. CRP was also significantly decreased from $0.203 \mathrm{mg} / \mathrm{L}$ to $0.073 \mathrm{mg} / \mathrm{L}$ in participants after the 8 week period of fatty fish and fish oil consumption $(p<0.008)$. These data provide evidence that an 8 week intervention period is sufficient to experience a change in the composition of red blood cell membranes and that an increased consumption of n-3 fatty acids from fish and fish oil reduces levels of CRP. However, because the high n-3 diet contained both fish and fish oil supplements, it is impossible to determine which had a more significant, if any, contribution to the reduced CRP levels. Further studies are needed to determine if fish consumption alone has the ability to reduce CRP levels. 
While epidemiological studies have shown mixed results regarding the relationship between increased consumption of fish oil and n-3 fatty acids and CRP levels, promising results have been seen with fatty fish consumption. This beneficial relationship could be a result of consuming the $\mathrm{n}-3$ fatty acids from a whole food as opposed to a supplement or because of other components present in fish, but not in fish oil supplements. To date, there has been one clinical trial published investigating the role of fatty fish consumption with additional fish oil supplementation on CRP levels; there are no known studies investigating the role of fatty fish consumption on CRP levels. With the potential for reduced CRP levels to decrease the risk for CHD, there is a need for additional intervention studies to determine if a causal relationship exists between fish consumption and CRP levels.

In West Virginia, fish and n-3 consumption are very low and CHD rates are very high. ${ }^{2}$ Increasing fatty fish consumption could potentially play a major role in reducing the incidence of CHD in this population. The availability of n-3 enhanced trout from the WVU Aquaculture program has provided the opportunity to determine if a causal relationship exists between fish consumption and CRP levels in post-menopausal women, a group at high risk for CHD, living in West Virginia. The results from this study will add to the current understanding of dietary roles as a preventative measure for $\mathrm{CHD}$ in post-menopausal women. 


\section{STUDY OBJECTIVES}

It has been suggested that a diet high in omega-3 fatty acids will have a beneficial effect on markers of cardiovascular risk in post-menopausal women. Fatty fish are a rich source of omega-3 fatty acids. Based on a review of the current literature we generated the following hypothesis: the risk of coronary heart disease (CHD) in post-menopausal women, as measured by C-reactive protein (CRP), will be reduced by consuming two servings per week of omega-3 enriched fish when compared to a control group consuming an unmodified diet. We tested this hypothesis with 3 specific aims by comparing a group of post-menopausal women who consumed two servings of omega-3 enriched fish to a control group consuming no-fish and limited omega-3 products.

1. To determine the mean change in serum high sensitivity $\mathrm{C}$-reactive protein (hsCRP) and compare the mean change between the two groups.

2. To determine the effect of other dietary and lifestyle factors on CRP levels.

3. To compare the mean change in traditional markers of cardiovascular disease risk including: total cholesterol, HDL cholesterol, LDL cholesterol, VLDL cholesterol and triglycerides between the two groups. 


\section{MATERIALS AND METHODS}

\section{Subjects}

The Institutional Review Board at West Virginia University (WVU) approved this research study. Participants were recruited from the WVU and Morgantown, WV communities using on campus fliers and word of mouth. Additionally, electronic announcements were posted in the WVU faculty E-News messaging system, and intranets at Ruby Memorial and Monongalia General Hospitals. The flier distributed on campus and adapted for electronic format can be seen in Appendix 1. Interested participants were screened for the following criteria:

Inclusionary: Post-menopausal (no menses within the prior 12 months or surgical menopause.

Exclusionary: severe obesity (BMI>40); personal history of coronary heart disease (myocardial infarction, congestive heart failure, angina, stroke); recent major infection or injury; chronic inflammatory disease (rheumatoid arthritis, cirrhosis, pulmonary/cystic fibrosis, glomerulosclerosis, chronic pancreatitis, inflammatory bowel disease, ulcerative colitis or psoriasis); current cancer; current anti-inflammatory medication; daily aspirin or ibuprofen usage; hormone replacement therapy (HRT); current tamoxifen usage; current fish oil or omega-3 supplement usage; current alcohol consumption greater than 1 serving per day; current smoker; current fatty fish consumption of 1 serving per week or greater; current consumption of omega-3 enhanced food products.

Participants who were previously on HRT, but had not taken within the 3 months prior to the start of the study were not excluded. Participants who were willing to stop all of the following for the duration of the study were also not excluded: daily anti-inflammatory, aspirin and/or ibuprofen usage; current fish oil or omega-3 supplement usage; current fatty fish consumption of 1 serving per week or greater; current consumption of omega-3 enhanced food products. Exclusionary criteria were selected to exclude participants diagnosed with cardiovascular disease 
or inflammatory diseases and to decrease factors that would interfere with inflammatory processes in the body. After screening, participants were randomly assigned to the experimental (fish) group or the control (no-fish) group by a computer generated randomization.

Study participants were required to attend a pre-study meeting in which study procedures were explained and subjects provided informed consent and waivers of privacy rights regarding protected health information (HIPAA). Study instructions were delivered in verbal and written form. After reviewing study instructions, participants were given the opportunity to ask questions or withdraw from the study. Participants were given a study folder that included study instructions, a calendar detailing expectations for the duration of the study, recommendations for a heart healthy diet, handouts for estimating portion sizes, food diary forms, blood work forms and copies of all documents signed. Members of the experimental group also received a blank calendar to record when servings of fish were eaten and recipes for preparing the fish. Participants also completed a baseline survey and the International Physical Activity Questionnaire (IPAQ) short form. ${ }^{36}$ At the completion of the study, participants were required to attend a post-study meeting where they completed an end of study survey and received copies of their food diary analysis, bloodwork tests and a form explaining how to interpret these results. These documents can be seen in Appendix 2.

Sample size calculations estimated that 51 participants were needed to obtain a significance level of 0.05 and power of $80 \%$ for a $0.5 \mathrm{mg} / \mathrm{L}$ difference in CRP levels. To account for a potential $20 \%$ attrition rate, a minimum of 60 participants were to be recruited. Forty women were screened and consented between June 2008 and April 2009. Four of the subjects withdrew before the study started, six dropped out during the study and one completed all but the pre- and post-study food logs. A total of 29 women completed the study, 15 in the experimental 
(fish) group and 14 in the control (no-fish) group fish $(\mathrm{n}=15)$ and no-fish $(\mathrm{n}=14)$ groups. Bloodwork data are presented for 30 participants due to one experimental group participant completing both blood tests, but no food diaries (fish group, $\mathrm{n}=16$ ).

\section{Diet Instructions}

At the initial screening, participants were instructed to refrain from consuming fish, any seafood, omega-3 enhanced/rich foods and daily anti-inflammatory medications through the duration of the study. At the pre-study meeting, participants were given additional dietary advice. They were asked to eliminate the above items as well as follow a heart healthy diet that is low in fat and rich in fruits and vegetables for the duration of the study. Appendix 2 contains the handout provided to participants listing heart healthy foods. Participants in the experimental group were to include two servings of the fish provided by the study each week for 8 weeks (study weeks 2-9). All participants were required to complete a seven day food diary during weeks 1 and 9 of the study. The diary could be hand written on the blank food diary form distributed during the pre-study meeting or completed on an electronic version that was available by request. Table 1 outlines the 12 week schedule the experimental group participants were provided. The schedule for the control group was identical with the exception of the instructions for week 2-8. During this time they were instructed to follow a heart healthy diet without any fish, seafood or omega-3 enhanced products. To increase compliance with the study protocol, weekly emails were sent to participants that included heart healthy tips and a reminder of the study requirements for the following week. 
Table 1: 12 week schedule for fish group participants.

\begin{tabular}{|l|l|}
\hline Week & $\begin{array}{l}\text { Beginning of study meeting: participants received packets containing: } \\
\text { - Instructions for study }\end{array}$ \\
0 & $\begin{array}{l}\text { - Heart healthy tips } \\
\text { - LabCorp and food diary forms } \\
\text { - Study intake and exercise questionnaires } \\
\text { Participants complete informed consent and HIPPA forms. }\end{array}$ \\
\hline 1 & All participants have baseline blood test at LabCorp and complete 7 day food diary. \\
\hline 2 & $\begin{array}{l}\text { Participants return food diary. } \\
\text { Fish group members receive fish; consume 2 servings. }\end{array}$ \\
\hline 3 & Fish group members consume 2 servings of fish. \\
\hline 4 & Fish group members consume 2 servings of fish. \\
\hline 5 & Fish group members consume 2 servings of fish. \\
\hline 6 & Fish group members consume 2 servings of fish. \\
\hline 7 & Fish group members consume 2 servings of fish. \\
\hline 8 & Fish group members consume 2 servings of fish. \\
\hline 9 & $\begin{array}{l}\text { Fish group members consume } 2 \text { servings of fish. } \\
\text { All participants complete and return } 7 \text { day food diary. }\end{array}$ \\
\hline 10 & All participants have end of study blood test at LabCorp. \\
\hline 11 & $\begin{array}{l}\text { End of study meeting where: } \\
- \text { Participants complete an evaluation of the study } \\
- \text { Participants receive results from food intake analysis and blood tests }\end{array}$ \\
\hline
\end{tabular}

\section{Fish}

The fish used in the study were omega-3 enhanced brook trout raised by Dr. Ken Semmens of the WVU Extension Service and Dr. Jacek Jaczynski from the Department of Animal and Nutritional Sciences. The fish were raised on a diet enriched with omega-3 fatty acids ( $42 \%$ by weight of diet). The omega-3 content of the fish was analyzed by Dr. Jaczynski's lab. The fish were requested to be cut into approximately $4 \mathrm{oz}$ fillets, vacuum sealed and flash frozen. The mean weight of a sample of 21 fillets was 4.67 ounces $(\mathrm{SD}=0.55)$. Participants received the vacuum sealed fillets with safe handling instructions and suggestions for preparation. (Appendix 2) Participants had the option of receiving all 16 fillets at one time or arranging to pick up smaller amounts of fillets throughout the study. The fatty acid composition 
of the brook trout consuming a flax enhanced diet compared to a control diet can be seen in Table $2 .^{37}$

Table 2: Fatty Acid Composition of Brook Trout

\begin{tabular}{|ccc|c|c|c|c|}
\cline { 3 - 7 } & & \multicolumn{5}{c|}{$\%$ \%A in total Fatty Acids } \\
Treatment & Total Fat in a Fillet & Total Omega 3 FA & Other & DHA & EPA & ALA \\
\hline Control & $4.50 \%$ & 26.31 & 3.9 & 14.45 & 5.17 & 2.79 \\
\hline Flax & $4.30 \%$ & 32.8 & 4.3 & 11.09 & 3.83 & 13.58 \\
\hline
\end{tabular}

\section{Data Collection and Analysis}

Blood samples were drawn and analyzed by LabCorp facilities. CRP and IL-6 levels were assessed using an immunochemiluminometric assay (ICMA). Total cholesterol, HDL cholesterol and triglycerides were measured using an enzymatic test. LDL and VLDL levels were calculated based on the results of the other lipid measurements.

Diet records were analyzed using the Nutrition Data System (NDS) from the University of Minnesota. Three week days and one weekend day were randomly selected from all seven day food diaries submitted. Phone verification of the data entered into the NDS system was completed by asking participants about any food items that were unclear on their food diary.

Total omega-3 consumption for the experimental group was calculated using nutrient values from NDS and data presented by Dr. Ken Semmens (Table 2). The additional quantity of omega-3 fatty acids present in the enhanced fish compared to brook trout in the NDS system was determined. The additional quantity of omega-3 fatty acids consumed from two fish fillets was averaged over 7 days to compute a daily additional omega- 3 consumption amount. This value was then added to the average daily value of omega-3 consumed as determined in NDS from the end of study food diary for the experimental group.

Demographic and physical activity data were obtained from self-administered surveys during the pre-study meeting. An exit survey was administered at the post-study meeting to 
determine participant satisfaction and any major health-related events (weight loss, cardiac event) that may have occurred during the study. The short International Physical Activity Questionnaire (IPAQ) was used to obtain physical activity data. ${ }^{36}$ Participants in the experimental group recorded the days and meals in which the fish was consumed using a "fish calendar" provided at the pre-study meeting.

\section{Statistical Analysis}

Descriptive statistics were computed for demographic and lifestyle characteristics. Change in biometric measures and intake were calculated by subtracting the pre-study from the post-study value for each item. IL-6 was reported as numerical values above 2 or "less than 2", making it difficult to quantify change in IL-6 values. To determine change in risk for CVD associated with change in IL-6, it was assumed that values less than 2 were low risk and values above 2 were high risk. ${ }^{38}$ A t-test was then used to compare mean change in total cholesterol, HDL, LDL, VLDL, triglycerides, CRP and IL-6, as well as mean change in intake of total fat, saturated fat, trans fat, total omega-3 fatty acids, omega- 6 fatty acids in the form of linoleic acid and fiber by group. Biometric measures and dietary components were compared within group pre- and post-study using a paired t-test. Finally, chi squared tests were performed to compare the proportion of participants in the experimental and control groups who experienced an increase to those who experienced a decrease or no change for total cholesterol, HDL, LDL, VLDL and triglycerides. A similar test was run to compare the proportion of participants in each group that experienced an increase to those who experienced a decrease or no change in CVD risk as defined by levels of CRP and IL-6. All statistical analysis were performed using Stata for Windows, Version 10.1. 


\section{RESULTS}

Demographic and lifestyle characteristics and for the study population are presented in Tables 3 and 4. These data represent the 37 women who completed the pre-study survey including the six women who dropped out prior to completion of the study and the single participant who completed a majority of the study but did not complete either food diary. Of the 14 women enrolled in the no-fish group, one was single, 11 were married and two were widowed. In the fish group, two were single, eight married, one widowed and four divorced. Among the participants who did not complete the study, one was single, five were married and was one divorced. There were no significant differences in marital status between any of the groups $(p=0.35)$. All participants had received a high school diploma, GED or higher. All participants in the no-fish group, all participants that dropped out and all but one in the fish group reported their race/ethnicity as white, non-Hispanics. One member of the fish group reported her race/ethnicity as African American, non-Hispanic. There were no significant differences between education level or race/ethnicity between any of the groups ( $p=1$ and $p=0.54$, respectively). There were no significant differences in mean age or body mass index (BMI) between groups ( $p=0.43$ and $p=0.50$, respectively). 
Table 3: Demographic Characteristics

\begin{tabular}{|c|c|c|c|c|}
\hline & No-Fish & Fish & Drop Out & $p^{7}$ \\
\hline & $\mathrm{n}=14$ & $n=16$ & $n=7$ & \\
\hline & $n(\%)$ & $\mathrm{n}(\%)$ & $\mathrm{n}(\%)$ & \\
\hline Marital Status & & & & 0.35 \\
\hline Single & $1(7.14)$ & $2(13.3)$ & $1(14.3)$ & \\
\hline Married & $11(78.6)$ & $8(53.3)$ & $5(71.4)$ & \\
\hline Widowed & $2(14.3)$ & $1(6.7)$ & $1(14.3)$ & \\
\hline Divorced & 0 & $4(26.7)$ & 0 & \\
\hline Education & & & & 1.00 \\
\hline Grade school or less & 0 & 0 & 0 & \\
\hline High school or GED & $3(21.4)$ & 0 & $1(14.3)$ & \\
\hline Some College & $1(7.1)$ & $2(13.3)$ & $1(14.3)$ & \\
\hline College & $4(28.6)$ & $6(40.0)$ & $3(42.9)$ & \\
\hline Graduate Degree & $6(42.9)$ & $9(46.7)$ & $2(28.6)$ & \\
\hline Race & & & & 0.54 \\
\hline White (non-Hispanic) & $14(100)$ & $14(93.3)$ & $7(100.0)$ & \\
\hline $\begin{array}{r}\text { African American (non- } \\
\text { Hispanic) }\end{array}$ & 0 & $1(6.7)$ & 0 & \\
\hline & Mean (SD) & Mean (SD) & Mean (SD) & $p^{2}$ \\
\hline Age (years) & $57.7(6.9)$ & $59.3(8.4)$ & $55.0(6.6)$ & 0.43 \\
\hline BMI $\left(\mathrm{kg} / \mathrm{m}^{2}\right)$ & $26.7(4.8)$ & $27.7(5.3)$ & $29.5(5.8)$ & 0.50 \\
\hline
\end{tabular}

${ }^{1}$ chi squared test; ${ }^{2}$ ANOVA; significance at $p<0.05$

Ten participants reported a history of smoking, three in the no-fish group, three in the fish group and four among the participants that dropped out. There were no significant differences in smoking history between groups $(p=0.25)$. Exercise frequency reported by the no-fish group on the pre-study questionnaire was $28.6 \%$ a few times a week, $50 \%$ once a week and $21.5 \%$ less than once a week. In the fish group, $37.5 \%$ exercised a few times a week $50 \%$ once a week and $12.5 \%$ less than once a week. All participants that dropped out of the study reported exercising once a week. There were no significant differences between groups in exercise frequency $(p=0.52)$ or in energy intensity as measured by the IPAQ-short form $(p=0.52)$. A majority of the population of both groups consumed alcohol a few times a month or less. 
Table 4: Lifestyle Characteristics

\begin{tabular}{|r|c|c|cc|}
\hline & No-Fish & Fish & Drop Out & $p^{I}$ \\
\hline & $\mathrm{n}(\%)$ & $\mathrm{n}(\%)$ & $\mathrm{n}(\%)$ & \\
\hline Smoking History & $\mathrm{n}=14$ & $\mathrm{n}=16$ & $\mathrm{n}=7$ & 0.25 \\
\hline Used to smoke, quit & $3(21.4)$ & $3(18.8)$ & $4(57.1)$ & \\
\hline Never smoked & $11(78.6)$ & $13(81.2)$ & $3(42.8)$ & \\
\hline Exercise Frequency & $\mathrm{n}=14$ & $\mathrm{n}=15$ & $\mathrm{n}=4$ & 0.52 \\
\hline A few times a week & $4(28.6)$ & $6(37.5)$ & 0 & \\
\hline Once a week & $7(50.0)$ & $8(50.0)$ & $3(100.0)$ & \\
\hline Less than once a week & $3(21.4)$ & $2(12.5)$ & 0 & \\
\hline Alcohol Frequency & $\mathrm{n}=14$ & $\mathrm{n}=15$ & $\mathrm{n}=8$ & 0.68 \\
\hline E few times a week & $1(7.1)$ & $2(13.3)$ & $1(12.5)$ & \\
\hline A few times a month & $1(7.1)$ & $1(6.7)$ & $1(12.5)$ & \\
\hline A few times a year & $3(21.4)$ & $2(13.3)$ & $3(37.5)$ & \\
\hline I never drink alcohol & $6(42.9)$ & $7(46.7)$ & $2(25.0$ & \\
\hline & Mean (SD) & Mean (SD) & Drop out & $p^{2}$ \\
\hline & $\mathrm{n}=14$ & $\mathrm{n}=16$ & $\mathrm{n}=3$ & 0.52 \\
\hline $\begin{array}{l}\text { Exercise Intensity (MET- } \\
\text { min/week) }\end{array}$ & 2511.1 & 1605.6 & 1816.2 & \\
\hline
\end{tabular}

${ }^{1}$ chi squared test; ${ }^{2}$ ANOVA; significance at $p<0.05$

Food diary analysis indicated that participants in the no-fish group did not significantly vary their diet over the course of the study. As can be seen in Table 5, the no-fish group had similar intake of total fat $(p=0.96)$, total omega-3 $(p=0.14)$, omega- 6 in the form of linoleic acid $(p=0.37)$, saturated fat $(p=0.79)$ and trans fat $(p=0.52)$ between the initial and final food diaries. There was a slight decrease in fiber intake from pre- to post-study in the no-fish group, however this comparison was not significant $(p=0.07)$. In the fish group there were significant differences in mean total omega-3 and mean fiber consumption pre- and post-study. Mean omega-3 consumption increased from 1.2 to 1.9 grams/day $(p=0.004)$. Mean fiber intake increased from 22.8 grams/day to 24.5 grams/day ( $p=0.04$ ). No significant differences were evident in the mean intake of total fat, omega- 6 , saturated fat or trans fat. The mean differences in fat intake pre- to post-study between the two study groups were not significant; total fat $(p=0.34)$, total omega-3 
$(p=0.11)$, omega-6 $(p=0.95)$, saturated fat $(p=0.24)$ or trans fat $(p=0.11)$. (Table 6) However,

fiber intake decreased in the no-fish group and increased in the fish group $(p=0.007)$.

Table 5: Pre- and Post-Study Mean Intakes for Fat and Fiber, Within Group Comparisons

\begin{tabular}{|c|c|c|c|c|c|c|}
\hline & \multicolumn{2}{|c|}{ No-Fish $(\mathrm{n}=14)$} & \multicolumn{4}{|c|}{ Fish $(n=15)$} \\
\hline & Pre-Study & Post-Study & & Pre-Study & Post-Study & \\
\hline & Mean (SE) & Mean (SE) & $p$ & Mean (SE) & Mean (SE) & $p$ \\
\hline Total Fat (g/day) & $55.2(5.5)$ & $55.6(9.9)$ & 0.96 & $55.9(5.1)$ & $65.4(6.0)$ & 0.11 \\
\hline Total Omega-3 (g/day) & $1.1(0.1)$ & $1.4(0.2)$ & 0.14 & $1.2(0.6)$ & $1.9(0.2)$ & 0.004 \\
\hline Omega-6(g/day Linoleic Acid & $9.7(1.0)$ & $11.5(2.1)$ & 0.37 & $10.8(1.3)$ & $12.4(1.5)$ & 0.3 \\
\hline Saturated Fat (g/day) & $19.3(2.5)$ & $18.5(3.6)$ & 0.79 & $19.2(2.2)$ & $22.4(2.0)$ & 0.09 \\
\hline Trans Fat (g/day) & $2.8(0.5)$ & $2.4(0.7)$ & 0.52 & $2.3(0.3)$ & $3.1(0.5)$ & 0.08 \\
\hline Fiber (g/day) & $21.4(1.6)$ & $18.9(1.8)$ & 0.07 & $22.8(1.9)$ & $24.5(2.0)$ & 0.04 \\
\hline
\end{tabular}

Significance at $p<0.05$; paired t-test.

Table 6: Mean Change in Fat and Fiber Intakes Pre- and Post-Study, between Group Comparisons

\begin{tabular}{|c|c|c|c|}
\hline & $\begin{array}{c}\text { No-Fish } \\
\text { n=14 } \\
\text { Mean (SE) }\end{array}$ & $\begin{array}{c}\text { Fish } \\
\mathrm{n}=15 \\
\text { Mean (SE) }\end{array}$ & $p$ \\
\hline Total Fat (g/day) & $0.4(7.7)$ & $9.5(5.6)$ & 0.34 \\
\hline Total Omega-3 (g/day) & $0.3(0.2)$ & $0.7(0.2)$ & 0.11 \\
\hline Omega-6 (g/day Linoleic Acid) & $1.8(1.9)$ & $1.6(1.5)$ & 0.95 \\
\hline Saturated Fat (g/day) & $-0.8(2.9)$ & $3.2(1.7)$ & 0.24 \\
\hline Trans Fat (g/day) & $-0.4(0.6)$ & $0.8(0.4)$ & 0.11 \\
\hline Fiber (g/day) & $-2.5(1.3)$ & $1.7(0.7)$ & 0.007 \\
\hline
\end{tabular}

Mean change calculated as post-study value minus pre-study value. Significance at $p<0.05$; $t$ test.

Table 7 presents baseline and post study biochemical measurements by group. Pre- and post-study data include the 29 participants that completed the study and the one participant that completed all but the food diaries. There were no significant differences in baseline total CHL, HDL, LDL, VLDL, triglycerides or CRP values between the no-fish and fish groups. Similar results were seen for the post-study measurements. There were no significant differences in the 
mean change of the biochemical measurements between the fish and no-fish groups or within groups. (Tables 8 and 9)

Table 7: Pre- and Post-Study Mean Lipid Levels and CRP, Between Group Comparisons

\begin{tabular}{|c|c|c|c|c|c|c|}
\hline & $\begin{array}{c}\text { No-Fish } \\
\text { n=14 } \\
\text { Mean (SE) }\end{array}$ & $\begin{array}{c}\text { Fish } \\
\mathrm{n}=16 \\
\text { Mean (SE) }\end{array}$ & $p$ & $\begin{array}{c}\text { No-Fish } \\
\mathrm{n}=14 \\
\text { Mean (SE) }\end{array}$ & $\begin{array}{c}\text { Fish } \\
\mathrm{n}=16 \\
\text { Mean (SE) }\end{array}$ & $p$ \\
\hline Total CHL (mg/dL) & $198.8(8.7)$ & $188(7.5)$ & 0.36 & $200.1(8.0)$ & $193(7.0)$ & 0.51 \\
\hline $\mathrm{HDL}(\mathrm{mg} / \mathrm{dL})$ & $67.4(5.0)$ & $66.8(3.6)$ & 0.91 & $67.0(4.3)$ & $65.4(3.5)$ & 0.77 \\
\hline $\mathrm{LDL}(\mathrm{mg} / \mathrm{dL})$ & $107.3(8.0)$ & $101.5(7.0)$ & 0.59 & $109.6(8.0)$ & $108.1(7.6)$ & 0.90 \\
\hline VLDL (mg/dL) & $24.1(4.4)$ & $19.8(2.2)$ & 0.37 & $23.5(3.6)$ & $19.5(1.8)$ & 0.31 \\
\hline Triglycerides (mg/dL) & $120.4(22.2)$ & $98.5(11.0)$ & 0.37 & $117.8(18.2)$ & $97.5(9.0)$ & 0.31 \\
\hline $\mathrm{CRP}(\mathrm{mg} / \mathrm{L})$ & $1.5(0.4)$ & $3.9(1.6)$ & 0.17 & $1.8(0.4)$ & $2.5(0.6)$ & 0.34 \\
\hline
\end{tabular}

Significance at $p<0.05$; $t$-test.

Table 8: Mean Change in Lipid Levels, Pre- and Post-Study, Between Group Comparisons

\begin{tabular}{|l|c|c|c|}
\multicolumn{1}{c}{} & $\begin{array}{c}\text { No-Fish } \\
\mathrm{n}=14\end{array}$ & \multicolumn{2}{c|}{$\begin{array}{c}\text { Fish } \\
\mathrm{n}=16\end{array}$} \\
& $\begin{array}{c}\text { Mean (SE) } \\
\text { Mean (SE) }\end{array}$ & $p$ \\
\hline Total CHL (mg/dL) & $1.3(4.5)$ & $5(6.1)$ & 0.6 \\
\hline HDL (mg/dL) & $-0.4(1.6)$ & $-1.4(1.3)$ & 0.7 \\
\hline LDL (mg/dL) & $2.3(4.2)$ & $6.6(4.6)$ & 0.5 \\
\hline VLDL (mg/dL) & $-0.6(1.8)$ & $-0.3(2.2)$ & 0.9 \\
\hline Triglycerides (mg/dL) & $-2.6(9.3)$ & $-1(11.0)$ & 0.9 \\
\hline CRP (mg/L) & $0.3(0.2)$ & $-1.4(1.6)$ & 0.3 \\
\hline
\end{tabular}

Mean change calculated as post-study value minus pre-study value. Significance at $p<0.05$; $t$ test.

Table 9: Pre- and Post-Study Mean Lipid Levels and CRP, Within Group Comparisons

\begin{tabular}{|c|c|c|c|c|c|c|}
\hline & \multicolumn{2}{|c|}{ No-Fish $(n=14)$} & \multicolumn{4}{|c|}{ Fish $(n=16)$} \\
\hline & Pre-Study & Post-Study & & Pre-Study & Post-Study & \\
\hline & Mean (SE) & Mean (SE) & $p$ & Mean (SE) & Mean (SE) & $p$ \\
\hline Total CHL (mg/dL) & $198.8(8.7)$ & $200.1(8.0)$ & 0.8 & $188(7.5)$ & $193(7.0)$ & 0.4 \\
\hline $\mathrm{HDL}(\mathrm{mg} / \mathrm{dL})$ & $67.4(5.0)$ & $67(4.3)$ & 0.8 & $66.8(3.6)$ & $65.4(3.5)$ & 0.3 \\
\hline $\mathrm{LDL}(\mathrm{mg} / \mathrm{dL})$ & $107.3(7.9)$ & $109.6(8.0)$ & 0.6 & $101.5(7.0)$ & $108.1(7.6)$ & 0.2 \\
\hline VLDL (mg/dL) & $24.1(4.4)$ & $23.5(3.6)$ & 0.8 & $19.8(2.2)$ & $19.5(1.8)$ & 0.9 \\
\hline Triglycerides (mg/dL) & $120.4(22.2)$ & $117.8(18.2)$ & 0.8 & $98.5(11.0)$ & $97.5(9.0)$ & 0.9 \\
\hline $\mathrm{CRP}(\mathrm{mg} / \mathrm{L})$ & $1.5(0.4)$ & $1.8(0.4)$ & 0.2 & $3.9(1.6)$ & $2.5(0.6)$ & 0.4 \\
\hline
\end{tabular}

Significance at $p<0.05$; paired t-test. 
There were no significant differences in the proportion of participants with increased lipid levels, CRP risk levels and IL-6 risk levels between the two groups. (Table 10)

Table 10: Proportion of Participants with Increased Lipid, CRP, and IL-6 Levels, Between Group Comparisons

\begin{tabular}{|c|c|c|c|c|c|}
\hline & \multicolumn{2}{|c|}{$\begin{array}{c}\text { No-Fish } \\
\text { n=14 } \\
n(\%)\end{array}$} & \multicolumn{2}{|c|}{$\begin{array}{l}\text { Fish } \\
n=16 \\
n(\%)\end{array}$} & \\
\hline & $\begin{array}{l}\text { Decrease or } \\
\text { No Change }\end{array}$ & Increase & $\begin{array}{l}\text { Decrease or } \\
\text { No Change }\end{array}$ & Increase & $p$ \\
\hline Total CHL (mg/dL) & $7(50.0)$ & $7(50.0)$ & $6(37.5)$ & $10(62.5)$ & 0.49 \\
\hline $\mathrm{HDL}(\mathrm{mg} / \mathrm{dL})$ & $8(57.1)$ & $6(42.9)$ & $10(62.5)$ & $6(37.5)$ & 0.77 \\
\hline LDL (mg/dL) & $6(42.9)$ & $8(57.1)$ & $5(31.3)$ & $11(68.8)$ & 0.51 \\
\hline VLDL (mg/dL) & $7(50.0)$ & $7(50.0)$ & $7(43.8)$ & $9(56.3)$ & 0.73 \\
\hline Triglycerides (mg/dL) & $6(42.9)$ & $8(57.1)$ & $7(43.8)$ & $9(56.3)$ & 0.96 \\
\hline CRP Risk Level & $12(85.7)$ & $2(14.3)$ & $14(87.5)$ & $2(12.5)$ & 0.89 \\
\hline IL-6 Risk Level & $11(78.6)$ & $3(21.4)$ & $11(73.3)$ & $4(26.7)$ & 0.74 \\
\hline
\end{tabular}

Significance at $p<0.05$; Chi squared test. 


\section{DISCUSSION}

The results of this study show that incorporating two servings of an omega-3 enhanced trout per week for 8 weeks into the diet of post-menopausal women was successful in increasing n-3 consumption; however no changes in markers of inflammation were seen as a result of the increased n-3 consumption.

Participants in both study groups were asked to follow a heart healthy diet omitting any foods high in omega-3 fatty acids, such as flax seeds, fish, seafood and omega-3 enhanced products for the duration of the study. Participants in the fish group significantly increased their average daily consumption of omega-3 fatty acids by $0.7 \mathrm{~g} /$ day $(\mathrm{SEM}=0.2)$, which was expected from the increased consumption of fish. An unexpected increase in omega-3 consumption was evident in the no-fish group (mean change=0.3 g/day $\mathrm{SEM}=0.2$ ), however the mean daily intake from end of study diet records was not significantly greater that the intake from the baseline diet records. This apparent increase in omega-3 intake in the control group likely reflects normal variation in the diets of individuals. When the mean change in intake was compared between the two groups the difference was not significant. Post-study mean omega-3 intake for the fish group was $1.9 \mathrm{~g}$ /day (SEM=0.2) and for the no-fish group was $1.4 \mathrm{~g} /$ day $(\mathrm{SEM}=0.2)$, both of which are greater than the $0.6 \mathrm{~g}$ /day recommended by Zampelas et al to maximize benefits. ${ }^{10}$ The amount of omega-3 consumed in this study is less than that reported in other studies. Tsitouras ${ }^{35}$ supplemented with 4-5 g/day of fish oil in addition to four 6-ounce servings of fish/week (n-3 content of fish not reported).

Elevated levels of the inflammatory marker CRP are associated with an increased risk of heart disease. ${ }^{4}$ The American Heart Association recommends consuming 2 servings of fatty fish per week to reduce the risk of CVD. ${ }^{39}$ Fatty fish are a rich source of the anti-inflammatory 
omega-3 fatty acids, the components in fish believed to produce the heart healthy benefits. In the present study, a non-significant decrease in CRP was seen in participants consuming two servings of an omega-3 enhanced fish per week. The lack of significance could be due to the small sample size of the study or the amount of omega- 3 fatty acids added to the diet in the form of fish was not sufficient to produce a significant change in CRP levels. Additionally, it is possible that the decrease in CRP levels, although not statistically significant, may be clinically significant. Individuals with CRP levels above $3 \mathrm{mg} / \mathrm{L}$ are considered at high risk for CVD, 1.0$3.0 \mathrm{mg} / \mathrm{L}$ are at medium risk and below $1.0 \mathrm{mg} / \mathrm{L}$ at low risk. The mean CRP levels changed from a high risk classification of $3.77 \mathrm{mg} / \mathrm{L}$ to a medium risk classification of $2.54 \mathrm{mg} / \mathrm{L}$ in the fish group. Tsitouras ${ }^{35}$ saw a significant, but smaller, change in CRP values than in the present study $(-0.127 \mathrm{mg} / \mathrm{L}$ versus $-1.23 \mathrm{mg} / \mathrm{L})$, however baseline CRP values were much higher in the present study $(3.77 \mathrm{mg} / \mathrm{L}$ versus $0.2 \mathrm{mg} / \mathrm{L}$ ). Participants in the Tsitouras study consumed 24 ounces of fish per week plus daily fish oil in comparison with 8 ounces of fish per week with no fish oil supplementation in the present study. Similar results may have been seen if participants in the current study had been provided with greater than 8 ounces of fish per week.

Based on the change in CRP levels over the course of the study, the majority of participants in the experimental group (87.5\%) experienced no change or a decrease in predicted CVD risk, only two experimental group participants experienced an increase in CVD risk based on CRP levels. While the proportion of subjects with decreased or no change in risk was not significantly different between the two groups, these results are supportive of an inverse association between omega-3 intake and CRP based CVD risk. Fiber consumption is a potential modifier of CRP levels. In this study, participants in the fish group significantly increased their 
fiber consumption compared to the no-fish group. This increased fiber consumption may have played a role in the decreased values of CRP in the fish group.

Elevated blood lipid levels including total cholesterol, LDL cholesterol, VLDL cholesterol and triglycerides and decreased HDL cholesterol levels are associated with increased CVD risk. Increased consumption of omega-3 fatty acids has been associated with decreases in blood triglyceride levels and increases in LDL and HDL cholesterols. ${ }^{39}$ It has been reported that $4 \mathrm{~g} /$ day intake of fish oil can result in a $25-30 \%$ decrease in triglyceride level, a 5-10\% increase in LDL and a 1-3\% increase in HDL. In this study an approximately $4 \%$ decrease in triglycerides, approximately $3 \%$ increase in LDL and approximately $2 \%$ decrease in HDL were seen in the experimental group participants. Within group and between group comparisons of blood lipid measures pre- and post-study were not significantly different. A majority of participants in both groups experienced no change in risk or decreased risk based on IL-6 levels.

There are several potential reasons why significant results may not have been seen in this study. In addition to those already mentioned (small sample size, need for more than 2 servings/week of fish), the composition of the fish fillets may explain the lack of significant results. As seen in Table 2, the composition of n-3 enhanced fish compared to control fish was greater in ALA than DHA and EPA. In fact, the presence of DHA and EPA decreased in fish consuming the flax oil diet. DHA and EPA are the omega-3 fatty acids associated with reduced risk for CHD. ALA can be converted to DHA and EPA in the body; however this conversion is very inefficient. ${ }^{29}$ Providing participants with control fish may have resulted in more promising results. Another potential reason a significant decrease in CRP was not seen in our study may be related to the demographics of the study population. Participants were relatively healthy individuals that did not smoke, drink, have heart disease and were not obese. Repeating the study 
with participants who would be considered unhealthy and have additional risk factors for heart disease (smoking, obesity, high cholesterol, do not exercise), may prove differing results. Lastly, participants in the fish group had a non-significant increase in total fat, saturated fat and trans fat consumption ( $p=0.11,0.09$ and 0.08 respectively). This increase could be due to participants preparing their fish in butter and would have an influence on several biomarkers measured in this study. A replica of this study providing smoked fish would decrease the variation in preparation methods and would eliminate the need to prepare the fish consuming butter.

There are some weaknesses in this study. First, the small sample size limited the statistical power of the analysis. Second, self reported food diaries are often a source of error. There could be inaccuracies in the serving sizes or brands reported. There is also potential for error in entering missing foods into the NDS program, however this error was minimized by having a second person verify the data that was entered. Calculating the additional omega-3 fatty acid content in the enhanced trout and incorporating that into the total n-3 consumed may have increased the error. This could be remedied in future studies by collecting the end of study food diary after participants have finished consuming their two servings of trout per week. One strength of this study was that participants were motivated and enjoyed consuming the fish. Another strength is that the participants were consuming fish from a uniform source, which would reduce any potential differences in $\mathrm{n}-3$ content in the fillets. 


\section{CONCLUSION}

In the present study, we were successful in showing that inclusion of two servings of an omega-3 enhanced fish per week significantly increased omega-3 consumption in a group of post-menopausal women. Non-significant decreases in CRP and triglycerides were seen in participants consuming the omega-3 enhanced fish, suggesting the potential for marine derived omega-3 fatty acids to decrease risk for CVD in post-menopausal women. Future studies on a larger scale need to be done to confirm the role of omega-3 enhanced fish on markers of heart disease in post-menopausal women. 


\section{REFERENCES}

1. American Heart Association. Heart disease and stroke statistics--2007 update. Circulation. 2007;115(5):e69-171.

2. American Heart Association. Heart disease and stroke statistics--2009 update. Circulation. 2009;119(3):e21-181.

3. Cardiac glossary. American Heart Association [Online]. April 28, 2008. Available at: http://www.americanheart.org. Accessed January 8, 2010.

4. Yeh ETH, Willerson JT. Coming of age of C-reactive protein: Using inflammation markers in cardiology. Circulation. 2003;107(3):370-371.

5. Ridker PM, Rifai N, Rose L, Buring JE, Cook NR. Comparison of C-reactive protein and low-density lipoprotein cholesterol levels in the prediction of first cardiovascular events. N Engl J Med. 2002;347(20):1557-1565.

6. Libby P. Inflammation and cardiovascular disease mechanisms. Am J Clin Nutr. 2006;83(2):456S-460.

7. King DE, Egan BM, Woolson RF, Mainous AG, III, Al-Solaiman Y, Jesri A. Effect of a high-fiber diet vs a fiber-supplemented diet on c-reactive protein level. Arch Intern Med. 2007;167(5):502-506.

8. Wells BJ, Mainous III AG, Everett CJ. Association between dietary arginine and creactive protein. Nutrition. 2005;21(2):125-130.

9. Giugliano D, Ceriello A, Esposito K. The effects of diet on inflammation: Emphasis on the metabolic syndrome. Journal of the American College of Cardiology. 2006;48(4):677-685.

10. Zampelas A, Panagiotakos DB, Pitsavos C. Fish consumption among healthy adults is associated with decreased levels of inflammatory markers related to cardiovascular disease: The ATTICA study. J. Am. Coll. Cardiol. 2005;46:120-124.

11. Colbert LH, Visser M, Simonsick EM, Tracy RP, Newman AB, Kritchevsky SB, Pahor M, Taaffe DR, Brach J, Rubin S, Harris TB. Physical activity, exercise, and inflammatory markers in older adults: Findings from the health, aging and body composition study. Journal of the American Geriatrics Society. 2004;52(7):1098-1104.

12. Ridker PM, Hennekens CH, Buring JE, Rifai N. C-reactive protein and other markers of inflammation in the prediction of cardiovascular disease in women. $N$ Engl J Med. 2000;342(12):836-843.

13. Yeh ETH, Anderson HV, Pasceri V, Willerson JT. C-reactive protein: Linking inflammation to cardiovascular complications. Circulation. 2001;104(9):974-975.

14. Zwaka TP, Hombach V, Torzewski J. C-reactive protein-mediated low density lipoprotein uptake by macrophages : Implications for atherosclerosis. Circulation. 2001;103(9):1194-1197.

15. Luc G, Bard J-M, Juhan-Vague I, Ferrieres J, Evans A, Amouyel P, Arveiler D, Fruchart J-C, Ducimetiere P. C-reactive protein, interleukin-6, and fibrinogen as predictors of coronary heart disease: The PRIME Study. Arterioscler Thromb Vasc Biol. 2003;23(7):1255-1261.

16. Madsen T, Christensen JH, Blom M, Schmidt EB. The effect of dietary n-3 fatty acids on serum concentrations of C-reactive protein: A dose-response study. British Journal of Nutrition. 2003;89(04):517-522. 
17. Garcia-Lorda P, Bullo M, Balanza R, Salas-Salvado J. C-reactive protein, adiposity and cardiovascular risk factors in a mediterranean population. 2005;30(3):468-474.

18. Danesh J, Wheeler JG, Hirschfield GM, Eda S, Eiriksdottir G, Rumley A, Lowe GDO, Pepys MB, Gudnason V. C-reactive protein and other circulating markers of inflammation in the prediction of coronary heart disease. $N$ Engl J Med. 2004;350(14):1387-1397.

19. Danesh J, Whincup P, Walker M, Lennon L, Thomson A, Appleby P, Gallimore JR, Pepys MB. Low grade inflammation and coronary heart disease: Prospective study and updated meta-analyses. BMJ. 2000;321(7255):199-204.

20. Mora S, Cook N, Buring JE, Ridker PM, Lee I-M. Physical activity and reduced risk of cardiovascular events: Potential mediating mechanisms. Circulation. 2007;116(19):21102118.

21. Jacob RA, Spinozzi GM, Simon VA, Kelley DS, Prior RL, Hess-Pierce B, Kader AA. Consumption of cherries lowers plasma urate in healthy women,. J. Nutr. 2003;133(6):1826-1829.

22. Sesso HD, Gaziano JM, Jenkins DJA, Buring JE. Strawberry intake, lipids, c-reactive protein, and the risk of cardiovascular disease in women. J Am Coll Nutr. 2007;26(4):303-310.

23. Yoneyama S, Miura K, Sasaki S, Yoshita K, Morikawa Y, Ishizaki M, Kido T, Naruse Y, Nakagawa H. Dietary intake of fatty acids and serum c-reactive protein in japanese. Journal of Epidemiology. 2007;17(3):86-92.

24. Murakami K, Sasaki S, Takahashi Y, Uenishi K, Yamasaki M, Hayabuchi H, Goda T, Oka J, Baba K, Ohki K, Muramatsu K, Sugiyama Y. Total n-3 polyunsaturated fatty acid intake is inversely associated with serum C-reactive protein in young Japanese women. 2008;28(5):309-314.

25. Kris-Etherton PM, Harris WS, Appel LJ, for the AHA Nutrition Committee. Omega-3 fatty acids and cardiovascular disease: New recommendations from the American Heart Association. Arterioscler Thromb Vasc Biol. 2003;23(2):151-152.

26. Wong KW. Clinical efficacy of n-3 fatty acid supplementation in patients with asthma. Journal of the American Dietetic Association. 2005;105(1):98-105.

27. Calder PC. N-3 polyunsaturated fatty acids, inflammation and immunity: Pouring oil on troubled waters or another fishy tale? Nutrition Research. 2001;21(1-2):309-341.

28. Yudkin JS, Kumari M, Humphries SE, Mohamed-Ali V. Inflammation, obesity, stress and coronary heart disease: Is interleukin-6 the link? Atherosclerosis. 2000;148(2):209214.

29. Anderson BM, Ma DW. Are all n-3 polyunsaturated fatty acids created equal? Lipids in Health and Disease. 2009;8(33).

30. Geelen A, Brouwer IA, Schouten EG, Kluft C, Katan MB, Zock PL. Intake of n-3 fatty acids from fish does not lower serum concentrations of C-reactive protein in healthy subjects. 2004;58(10):1440-1442.

31. Carrero JJ, Fonolla J, Marti JL, Jimenez J, Boza JJ, Lopez-Huertas E. Intake of fish oil, oleic acid, folic acid, and vitamins B-6 and E for 1 year decreases plasma C-reactive protein and reduces coronary heart disease risk factors in male patients in a cardiac rehabilitation program. J. Nutr. 2007;137(2):384-390. 
32. Kelley DS, Siegel D, Fedor DM, Adkins Y, Mackey BE. DHA supplementation decreases serum C-reactive protein and other markers of inflammation in hypertriglyceridemic men. J. Nutr. 2009;139(3):495-501.

33. Hu FB, Cho E, Rexrode KM, Albert CM, Manson JE. Fish and long-chain \{omega -3 fatty acid intake and risk of coronary heart disease and total mortality in diabetic women. Circulation. 2003;107(14):1852-1857.

34. Niu K, Hozawa A, Kuriyama S, Ohmori-Matsuda K, Shimazu T, Nakaya N, Fujita K, Tsuji I, Nagatomi R. Dietary long-chain n-3 fatty acids of marine origin and serum Creactive protein concentrations are associated in a population with a diet rich in marine products. Am J Clin Nutr. 2006;84(1):223-229.

35. Tsitouras PD, Gucciardo F, Salbe AD, Heward C, Harman SM. High omega-3 fat intake improves insulin sensitivity and reduces crp and il6, but does not affect other endocrine axes in healthy older adults. Horm Metab Res. 2008;40(03):199-205.

36. Craig CL, Marshall AL, Sjostrom M, Bauman AE, Booth ML, Ainsworth BE, Pratt M, Ekelund ULF, Yngve A, Sallis JF, Oja P. International physical activity questionnaire: 12-country reliability and validity. Medicine \& Science in Sports \& Exercise August 2003;35(8):1381-1395. 2003.

37. Semmens K. (2009). [Comparing brook and rainbow flax expt 10.8.09]. Unpublished raw data.

38. Ridker PM, Rifai N, Stampfer MJ, Hennekens CH. Plasma concentration of interleukin-6 and the risk of future myocardial infarction among apparently healthy men. Circulation. 2000;101(15):1767-1772.

39. Kris-Etherton PM, Harris WS, Appel LJ, for the Nutrition Committee. Fish consumption, fish oil, omega-3 fatty acids, and cardiovascular disease. Circulation.

2002;106(21):2747-2757. 
APPENDIX 1: Advertisements

- Flier Posted on Campus (2 pages)

- Electronic Announcement 


\section{$\vartheta$ FiSH ANO YOUR HERT}

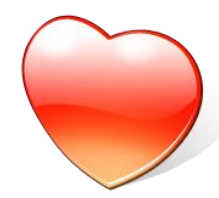

The Human Nutrition and Foods Program at WVU is looking for postmenopausal women for a research project conducted by Dr. Cindy Fitch about nutrition and C-reactive protein, a screening test for heart disease. To qualify, you must be a woman who:

- Has gone through natural or surgical menopause.

- Is not taking hormone replacement therapy.

- Does not have a chronic inflammatory disease.

- Has not been diagnosed with any type of heart disease.

- Does not currently smoke.

The study will take place in the Morgantown area between April and June 2009. All participants will be asked to follow a heart healthy diet and some will be asked to eat two servings of fish each week, which will be provided free of charge. Participants in this study will be asked to:

- Attend an informational group meeting.

- Complete pre- and post- assessment surveys.

- Keep track of your food and drink intake for two 7-day periods.

- Keep track of your fish intake during the 8 week study period.

- Have blood drawn at a local LabCorp facility at the beginning and end of the study.

- Keep from consuming any omega-3 enhanced food products, fish not provided by the study or fish oil supplements during the study.

The total time commitment is expected to be about 3 hours at the beginning and the end of the study.

For more information, call Cindy Fitch at 293-2796 ext. 3341 or email troutstudy@mail.wvu.edu

Deadline to enroll in study: April 5, 2009

IRB approval on file, please contact

Cindy Fitch to request a copy.

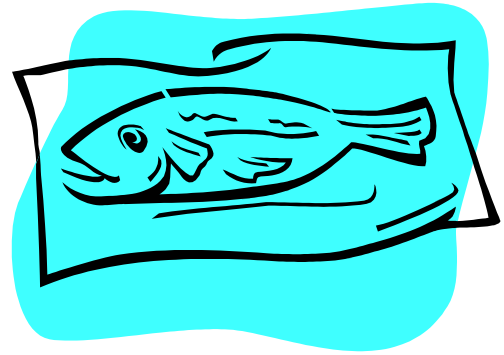




\section{Facts about Heart Disease}

- Leading cause of death in the United States and in West Virginia.

- Approximately $40 \%$ of all deaths are due to heart disease and stroke.

- West Virginia has the third highest rate of death from heart disease.

- Rates are 2-3 times greater among postmenopausal women.

- $64 \%$ of women who die suddenly have no prior symptoms.

- Common risk factors include smoking, high cholesterol, high blood pressure, physical inactivity, obesity and diabetes

- New risk factors include markers of inflammation, such as C-reactive protein, which can be present when other risk factors are not.

- Consuming products that reduce inflammation may decrease risk for heart disease by reducing levels of C-reactive protein.

- Foods that may reduce inflammation include fatty fish, cherries, and fruits and vegetables. Eating a high fiber diet and participating in regular exercise may also reduce inflammation.

- Fatty fish are high in omega-3 fatty acids, which are known to reduce inflammation.

- Fatty fish include mackerel, trout, herring, sardines, albacore tuna and salmon.

- Consumption of fatty fish 1-2 times per week may reduce the risk for heart disease by decreasing levels of C-reactive protein in your body.

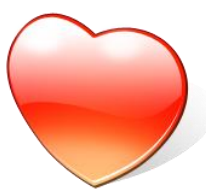

Sources:

American Heart Association

CDC Division for Heart Disease and Stroke Prevention

West Virginia Department of Health \& Human Resources 


\section{E-News Announcement}

The Human Nutrition and Foods Program at WVU is looking for postmenopausal women for a research project conducted by Dr. Cindy Fitch about nutrition and C-reactive protein, a screening test for heart disease. To qualify, you must be a woman

- who has gone through natural or surgical menopause,

- has not been diagnosed with any type of heart disease, and

- does not currently smoke.

Participating women will learn about heart healthy eating and half of them will eat fish each week for two months. You will be asked to

- attend an informational group meeting,

- fill out a survey,

- keep track of your food and drink intake, and

- have blood drawn at a local LabCorp facility at the beginning and end of the two months. The total time commitment is expected to be about 3 hours at the beginning and the end of the study (2 months). Fish will be provided free to participants who are assigned to the fish group. You may or may not be assigned to the "free fish" group. IRB approval for this study is on file. For more information, call Cindy Fitch at 293-2796 ext 3341. Deadline to apply is April 5, 2009. 


\section{APPENDIX 2: Participant Forms Pre and Post-Study}

- Fish Group Instructions (2 pages)

- No-Fish Group Instructions ( 2 pages)

- Recommendations for a Heart Healthy Diet

- Fish Calendar (fish group only)

- Food Diary Log (15 pages)

- Baseline Survey (3 pages)

- Trout Recipes (fish group only, 2 pages)

- Safe Handling Instructions

- IPAQ (2 pages)

- Informed Consent (5 pages)

- HIPAA (4 pages)

- End of Study Survey (2 pages)

- Post-Study Meeting Handout (2 pages) 


\section{Fish Group Instructions}

Welcome to the study! You have been selected to be a member of our "fish" group.

Throughout the next few weeks, we will be asking you to have blood work done at a local LabCorp facility, record everything you eat and drink for two 7 day periods and consume two servings of fish per week while following recommendations for a heart healthy diet. Tonight you will be receiving paperwork to have blood taken at LabCorp and your baseline food diary form. You will receive your fish at the end of next week (week 1) or the beginning of the following week (week 2) when you hand in your baseline food diary.

You may be wondering, what do I do next? Below is a timeline of what to expect over the course of the following weeks.

\begin{tabular}{|c|l|}
\hline Week & \multicolumn{1}{c|}{ Action } \\
\hline 0 & Attend Pre-Study Meeting \\
\hline 1 & Record Food Intake \\
\cline { 2 - 2 } & Blood work at LabCorp \\
\cline { 2 - 2 } & Hand in food log \\
\cline { 2 - 2 } & Pick up fish \\
\hline 2 & Eat 2 Servings of fish \\
\cline { 2 - 2 } 3 & Eat 2 Servings of fish \\
\cline { 2 - 2 } 4 & Eat 2 Servings of fish \\
\hline 5 & Eat 2 Servings of fish \\
\hline 6 & Eat 2 Servings of fish \\
\hline 7 & Eat 2 Servings of fish \\
\hline 8 & Eat 2 Servings of fish \\
\hline 9 & Eat 2 Servings of fish \\
\cline { 2 - 2 } & Record Food Intake \\
\hline 10 & Blood work at LabCorp \\
\hline 11 & Attend Post-Study Meeting \\
\cline { 2 - 2 } & Hand in food log \\
\hline
\end{tabular}

Food logs can be returned when you come to pick up your fish, mailing to the address provided or arranging a time to drop them off.

If you have any questions about the study, please contact Dr. Cindy Fitch at 304.293.2796 x 3341 or email troutstudy@ mail.wvu.edu

Thank you for your participation!

Visit the study's website at: http://www.caf.wvu.edu/afmdp/FishandYourHeart.html 


\section{Things to Do}

1. Eat a heart healthy diet.

2. Consume 2 servings of study provided fish per week.

3. Record everything you eat and drink during week 1 and week 9 .

4. Use the provided calendar to record when you eat the study fish.

5. Have blood drawn at LabCorp during week 1 and week 10.

6. Contact us if you start taking any medications or are diagnosed with an illness at any time throughout the study.

\section{Things to Avoid*}

1. Do not eat any fish other than what is provided for the study.

2. Do not consume and omega-3, DHA or EPA enhanced products.

3. Do not consume flax seed or flax seed oil.

4. Do not take fish oil supplements.

5. Do not take anti-inflammatory medications on a daily basis.

6. Do not start hormone replacement therapy.

*Please always follow the advice of your medical doctor. If your doctor prescribes medication that conflicts with study requirements, please contact us to stop participation in the study.*

\section{Local LabCorp Facilities:}

Internal Medicine Associates, Inc.

99 J.D. Anderson Drive

Morgantown, WV 26505

304-598-9761

Medical Arts Laboratory

200 Wedgewood Drive

Morgantown, WV 26505

304-599-8324

Lab Corp.

501 Locust Ave.

Fairmont, WV 26554

800-352-3141

Please visit https://www.newlabcorp.com/wps/portal/findalab to locate additional facilities in your area. 


\section{No-Fish Group Instructions}

Welcome to the study! You have been selected to be a member of our "no fish" group.

Throughout the next few weeks, we will be asking you to have blood work done at a local LabCorp facility, record everything you eat and drink for two 7 day periods and follow recommendations for a heart healthy diet. In addition, we would like for you to refrain from consuming any of the following during the study: fish, fish oils, omega-3 enhanced food and anti-inflammatory medications.

You may be wondering, what do I do next? Below is a timeline of what to expect over the course of the following weeks.

\begin{tabular}{|c|l|}
\hline Week & \multicolumn{1}{c|}{ Action } \\
\hline 0 & Attend Pre-Study Meeting \\
\hline 1 & Record Food Intake \\
\cline { 2 - 2 } & Blood work at LabCorp \\
\cline { 2 - 2 } & Hand in food log \\
\hline 2 & Eat Heart Healthy Diet \\
\cline { 2 - 2 } 3 & Eat Heart Healthy Diet \\
\cline { 2 - 2 } 4 & Eat Heart Healthy Diet \\
\hline 5 & Eat Heart Healthy Diet \\
\hline 6 & Eat Heart Healthy Diet \\
\hline 7 & Eat Heart Healthy Diet \\
\hline 8 & Eat Heart Healthy Diet \\
\hline 9 & Eat Heart Healthy Diet \\
\cline { 2 - 2 } & Record Food Intake \\
\hline 10 & Blood work at LabCorp \\
\hline 11 & Attend Post-Study Meeting \\
\cline { 2 - 2 } & Hand in food log \\
\hline
\end{tabular}

Food $\operatorname{logs}$ can be returned by mailing to the address provided or emailing troutstudy@mail.wvu.edu to arrange a time to drop them off.

If you have any questions about the study, please contact Dr. Cindy Fitch at 304.293.2796 x 3341 or email troutstudy @ mail.wvu.edu

Thank you for your participation!

Visit the study's website at: http://www.caf.wvu.edu/afmdp/FishandYourHeart.html 


\section{Things to Do}

7. Eat a heart healthy diet.

8. Record everything you eat and drink during week 1 and week 9.

9. Have blood drawn at LabCorp during week 1 and week 10.

10. Contact us if you start taking any medications at any time throughout the study.

\section{Things to Avoid*}

7. Do not eat any fish for the duration of the study.

8. Do not consume and omega-3, DHA or EPA enhanced products.

9. Do not consume flax seed or flax seed oil.

10. Do not take fish oil supplements.

11. Do not take anti-inflammatory medications on a daily basis.

12. Do not start hormone replacement therapy.

*Please always follow the advice of your medical doctor. If your doctor prescribes medication that conflicts with study requirements, please contact us to stop participation in the study.*

\section{Local LabCorp Facilities:}

Internal Medicine Associates, Inc.

99 J.D. Anderson Drive

Morgantown, WV 26505

304-598-9761

Medical Arts Laboratory

200 Wedgewood Drive

Morgantown, WV 26505

304-599-8324

Lab Corp.

501 Locust Ave.

Fairmont, WV 26554

800-352-3141

Please visit https://www.newlabcorp.com/wps/portal/findalab to locate additional facilities in your area. 


\section{Recommendations for a Heart Healthy Diet}

The American Heart Association recommends reducing overall fat intake to 25$35 \%$ of your daily calories with saturated fat less than $7 \%$ and trans fat less than $1 \%$ of your daily calories. In addition, they recommend a varied diet that includes fruits, vegetables and whole grains, is high in fiber (25-30 grams/day) and low in sodium (less than $2300 \mathrm{mg} /$ day or less than $1500 \mathrm{mg} / \mathrm{day}$ for those with high blood pressure). Below is a list of food items to include in a heart healthy diet.

- Skim or low-fat milk (1\%)

- Fat free or low fat dairy products such as cheese and yogurt

- Egg whites or egg substitutes

- Fish, especially fatty (no fish during the study!)

- Skinless poultry

- Legumes

- Soybeans and soy products

- Lean ground meats

- Fresh or frozen fruits and vegetables

- Low-sodium or rinsed canned vegetables

- Canned fruit packed in juice or water

- Whole wheat flour

- Whole grain bread, preferably $100 \%$ whole wheat or $100 \%$ whole grain

- High fiber cereal with 5 or more grams of fiber per serving

- Brown rice

- Whole-grain pasta

- Oatmeal (steel-cut or regular)

- Ground flaxseed (no flaxseed or flaxseed oil during the study!)

- Herbs and spices

- Reduced-salt canned soups or prepared meals

- Olive oil

- Canola oil

- Margarine labeled trans-fat free

*For more heart healthy recommendations visit the American Heart Association, American Dietetic Association and the Mayo Clinic on the web

*For recipe ideas visit: deliciousdecisions.org, goredforwomen.org, eatingwell.com, and cookinglight.com 


\section{Fish and Your Heart \\ Daily Food Record \\ Pre-Study Log}

Instructions: For seven days, starting this Sunday through the following Saturday, we would like you to keep a record of your dietary intake. Use the attached charts to keep track of the foods you eat on the selected days. Follow the instructions that have been provided in order to complete the most accurate daily food record possible.

- Record everything you eat and drink for $\mathbf{7}$ days. Include the date and day of the week at the top of each form. Start with the first thing you consume this Sunday and end with the last thing you consume the following Saturday. Each line of the food diary is for one food item, not an entire meal!

- Use a separate form for each day. Use more than one form if needed for one day, but begin a new form for each new day.

- Keep it with you. Carry the food record with you during the day. It is surprisingly difficult to recall what you ate hours or days later.

- Include details. Record anything added to the food such as sugar, ketchup, margarine or salad dressing.

- Describe combination foods. If you are eating a combination food such as pizza with various toppings, make sure to record all ingredients. Record brand names for packaged foods and restaurant names for foods eaten out.

- Save labels. When you can, please save the nutrient labels from the packaged foods you eat and bring them with you when you turn in your food log.

- Estimate serving size. To the best of your ability, estimate the serving size. Use the serving size on the food label if available. Use measuring cups and spoons at home. If you are uncertain, estimate using familiar objects. For example, you can use "palm of my hand" to estimate the size of a chicken breast or "baseball" to estimate a serving of ice cream.

- Record time. Record the approximate time each meal or snack is eaten.

- Write down beverages. Record all beverages that you consume. This includes no-calorie drinks such as diet sodas, unsweetened tea and water.

- Write down any vitamin or other supplements that you take. Include the brand name and amount you took.

- Bring the record and food labels with you when you pick up your fish! 
Fish and Your Heart

Daily Food Record

Day 1 - Pre-Study

Name:

Date:

Day of the Week: SUN MON TUES WED THUR FRI SAT

\begin{tabular}{|c|c|c|c|}
\hline Time & $\begin{array}{c}\text { Food/Drink } \\
\text { Type of food, brand name, } \\
\text { restaurant }\end{array}$ & $\begin{array}{l}\text { Method of Preparation } \\
\text { Description, product } \\
\text { label or recipe }\end{array}$ & $\begin{array}{l}\text { Amount } \\
\text { Tsp, tbsp, } \\
\text { cup, oz, } \\
\text { weight or } \\
\text { portion }\end{array}$ \\
\hline & & & \\
\hline & & & \\
\hline & & & \\
\hline & & & \\
\hline & & & \\
\hline & & & \\
\hline & & & \\
\hline & & & \\
\hline & & & \\
\hline & & & \\
\hline & & & \\
\hline & & & \\
\hline & & & \\
\hline & & & \\
\hline & & & \\
\hline & & & \\
\hline & & & \\
\hline & & & \\
\hline & & & \\
\hline & & & \\
\hline & & & \\
\hline & & & \\
\hline & & & \\
\hline
\end{tabular}




\begin{tabular}{|c|c|c|c|}
\hline Time & $\begin{array}{c}\text { Food/Drink } \\
\text { Type of food, brand name, } \\
\text { restaurant }\end{array}$ & $\begin{array}{l}\text { Method of Preparation } \\
\text { Description, product } \\
\text { label or recipe }\end{array}$ & $\begin{array}{l}\text { Amount } \\
\text { Tsp, tbsp, } \\
\text { cup, oz, } \\
\text { weight or } \\
\text { portion }\end{array}$ \\
\hline & & & \\
\hline & & & \\
\hline & & & \\
\hline & & & \\
\hline & & & \\
\hline & & & \\
\hline & & & \\
\hline & & & \\
\hline & & & \\
\hline & & & \\
\hline & & & \\
\hline & & & \\
\hline & & & \\
\hline & & & \\
\hline & & & \\
\hline & & & \\
\hline & & & \\
\hline & & & \\
\hline & & & \\
\hline & & & \\
\hline & & & \\
\hline & & & \\
\hline & & & \\
\hline
\end{tabular}


Fish and Your Heart

Daily Food Record

Day 2 - Pre-Study

Name:

Date:

Day of the Week: SUN MON TUES WED THUR FRI SAT

\begin{tabular}{|c|c|c|c|}
\hline Time & $\begin{array}{c}\text { Food/Drink } \\
\text { Type of food, brand name, } \\
\text { restaurant }\end{array}$ & $\begin{array}{l}\text { Method of Preparation } \\
\text { Description, product } \\
\text { label or recipe }\end{array}$ & $\begin{array}{l}\text { Amount } \\
\text { Tsp, tbsp, } \\
\text { cup, oz, } \\
\text { weight or } \\
\text { portion }\end{array}$ \\
\hline & & & \\
\hline & & & \\
\hline & & & \\
\hline & & & \\
\hline & & & \\
\hline & & & \\
\hline & & & \\
\hline & & & \\
\hline & & & \\
\hline & & & \\
\hline & & & \\
\hline & & & \\
\hline & & & \\
\hline & & & \\
\hline & & & \\
\hline & & & \\
\hline & & & \\
\hline & & & \\
\hline & & & \\
\hline & & & \\
\hline & & & \\
\hline & & & \\
\hline & & & \\
\hline
\end{tabular}




\begin{tabular}{|c|c|c|c|}
\hline Time & $\begin{array}{c}\text { Food/Drink } \\
\text { Type of food, brand name, } \\
\text { restaurant }\end{array}$ & $\begin{array}{l}\text { Method of Preparation } \\
\text { Description, product } \\
\text { label or recipe }\end{array}$ & $\begin{array}{l}\text { Amount } \\
\text { Tsp, tbsp, } \\
\text { cup, oz, } \\
\text { weight or } \\
\text { portion }\end{array}$ \\
\hline & & & \\
\hline & & & \\
\hline & & & \\
\hline & & & \\
\hline & & & \\
\hline & & & \\
\hline & & & \\
\hline & & & \\
\hline & & & \\
\hline & & & \\
\hline & & & \\
\hline & & & \\
\hline & & & \\
\hline & & & \\
\hline & & & \\
\hline & & & \\
\hline & & & \\
\hline & & & \\
\hline & & & \\
\hline & & & \\
\hline & & & \\
\hline & & & \\
\hline & & & \\
\hline
\end{tabular}


Fish and Your Heart

Daily Food Record

Day 3 - Pre-Study

Name:

Date:

Day of the Week: SUN MON TUES WED THUR FRI SAT

\begin{tabular}{|c|c|c|c|}
\hline Time & $\begin{array}{c}\text { Food/Drink } \\
\text { Type of food, brand name, } \\
\text { restaurant }\end{array}$ & $\begin{array}{l}\text { Method of Preparation } \\
\text { Description, product } \\
\text { label or recipe }\end{array}$ & $\begin{array}{l}\text { Amount } \\
\text { Tsp, tbsp, } \\
\text { cup, oz, } \\
\text { weight or } \\
\text { portion }\end{array}$ \\
\hline & & & \\
\hline & & & \\
\hline & & & \\
\hline & & & \\
\hline & & & \\
\hline & & & \\
\hline & & & \\
\hline & & & \\
\hline & & & \\
\hline & & & \\
\hline & & & \\
\hline & & & \\
\hline & & & \\
\hline & & & \\
\hline & & & \\
\hline & & & \\
\hline & & & \\
\hline & & & \\
\hline & & & \\
\hline & & & \\
\hline & & & \\
\hline & & & \\
\hline & & & \\
\hline
\end{tabular}




\begin{tabular}{|c|c|c|c|}
\hline Time & $\begin{array}{c}\text { Food/Drink } \\
\text { Type of food, brand name, } \\
\text { restaurant }\end{array}$ & $\begin{array}{l}\text { Method of Preparation } \\
\text { Description, product } \\
\text { label or recipe }\end{array}$ & $\begin{array}{l}\text { Amount } \\
\text { Tsp, tbsp, } \\
\text { cup, oz, } \\
\text { weight or } \\
\text { portion }\end{array}$ \\
\hline & & & \\
\hline & & & \\
\hline & & & \\
\hline & & & \\
\hline & & & \\
\hline & & & \\
\hline & & & \\
\hline & & & \\
\hline & & & \\
\hline & & & \\
\hline & & & \\
\hline & & & \\
\hline & & & \\
\hline & & & \\
\hline & & & \\
\hline & & & \\
\hline & & & \\
\hline & & & \\
\hline & & & \\
\hline & & & \\
\hline & & & \\
\hline & & & \\
\hline & & & \\
\hline
\end{tabular}


Fish and Your Heart

Daily Food Record

Day 4 - Pre-Study

Name:

Date:

Day of the Week: SUN MON TUES WED THUR FRI SAT

\begin{tabular}{|c|c|c|c|}
\hline Time & $\begin{array}{c}\text { Food/Drink } \\
\text { Type of food, brand name, } \\
\text { restaurant }\end{array}$ & $\begin{array}{l}\text { Method of Preparation } \\
\text { Description, product } \\
\text { label or recipe }\end{array}$ & $\begin{array}{l}\text { Amount } \\
\text { Tsp, tbsp, } \\
\text { cup, oz, } \\
\text { weight or } \\
\text { portion }\end{array}$ \\
\hline & & & \\
\hline & & & \\
\hline & & & \\
\hline & & & \\
\hline & & & \\
\hline & & & \\
\hline & & & \\
\hline & & & \\
\hline & & & \\
\hline & & & \\
\hline & & & \\
\hline & & & \\
\hline & & & \\
\hline & & & \\
\hline & & & \\
\hline & & & \\
\hline & & & \\
\hline & & & \\
\hline & & & \\
\hline & & & \\
\hline & & & \\
\hline & & & \\
\hline & & & \\
\hline
\end{tabular}




\begin{tabular}{|c|c|c|c|}
\hline Time & $\begin{array}{c}\text { Food/Drink } \\
\text { Type of food, brand name, } \\
\text { restaurant }\end{array}$ & $\begin{array}{l}\text { Method of Preparation } \\
\text { Description, product } \\
\text { label or recipe }\end{array}$ & $\begin{array}{c}\text { Amount } \\
\text { Tsp, tbsp, } \\
\text { cup, oz, } \\
\text { weight or } \\
\text { portion }\end{array}$ \\
\hline & & & \\
\hline & & & \\
\hline & & & \\
\hline & & & \\
\hline & & & \\
\hline & & & \\
\hline & & & \\
\hline & & & \\
\hline & & & \\
\hline & & & \\
\hline & & & \\
\hline & & & \\
\hline & & & \\
\hline & & & \\
\hline & & & \\
\hline & & & \\
\hline & & & \\
\hline & & & \\
\hline & & & \\
\hline & & & \\
\hline & & & \\
\hline & & & \\
\hline & & & \\
\hline
\end{tabular}


Fish and Your Heart

Daily Food Record

Day 5 - Pre-Study

Name:

Date:

Day of the Week: SUN MON TUES WED THUR FRI SAT

\begin{tabular}{|c|c|c|c|}
\hline Time & $\begin{array}{c}\text { Food/Drink } \\
\text { Type of food, brand name, } \\
\text { restaurant }\end{array}$ & $\begin{array}{l}\text { Method of Preparation } \\
\text { Description, product } \\
\text { label or recipe }\end{array}$ & $\begin{array}{l}\text { Amount } \\
\text { Tsp, tbsp, } \\
\text { cup, oz, } \\
\text { weight or } \\
\text { portion }\end{array}$ \\
\hline & & & \\
\hline & & & \\
\hline & & & \\
\hline & & & \\
\hline & & & \\
\hline & & & \\
\hline & & & \\
\hline & & & \\
\hline & & & \\
\hline & & & \\
\hline & & & \\
\hline & & & \\
\hline & & & \\
\hline & & & \\
\hline & & & \\
\hline & & & \\
\hline & & & \\
\hline & & & \\
\hline & & & \\
\hline & & & \\
\hline & & & \\
\hline & & & \\
\hline & & & \\
\hline
\end{tabular}




\begin{tabular}{|c|c|c|c|}
\hline Time & $\begin{array}{c}\text { Food/Drink } \\
\text { Type of food, brand name, } \\
\text { restaurant }\end{array}$ & $\begin{array}{l}\text { Method of Preparation } \\
\text { Description, product } \\
\text { label or recipe }\end{array}$ & $\begin{array}{l}\text { Amount } \\
\text { Tsp, tbsp, } \\
\text { cup, oz, } \\
\text { weight or } \\
\text { portion }\end{array}$ \\
\hline & & & \\
\hline & & & \\
\hline & & & \\
\hline & & & \\
\hline & & & \\
\hline & & & \\
\hline & & & \\
\hline & & & \\
\hline & & & \\
\hline & & & \\
\hline & & & \\
\hline & & & \\
\hline & & & \\
\hline & & & \\
\hline & & & \\
\hline & & & \\
\hline & & & \\
\hline & & & \\
\hline & & & \\
\hline & & & \\
\hline & & & \\
\hline & & & \\
\hline & & & \\
\hline
\end{tabular}


Fish and Your Heart

Daily Food Record

Day 6 - Pre-Study

Name:

Date:

Day of the Week: SUN MON TUES WED THUR FRI SAT

\begin{tabular}{|c|c|c|c|}
\hline Time & $\begin{array}{c}\text { Food/Drink } \\
\text { Type of food, brand name, } \\
\text { restaurant }\end{array}$ & $\begin{array}{l}\text { Method of Preparation } \\
\text { Description, product } \\
\text { label or recipe }\end{array}$ & $\begin{array}{l}\text { Amount } \\
\text { Tsp, tbsp, } \\
\text { cup, oz, } \\
\text { weight or } \\
\text { portion }\end{array}$ \\
\hline & & & \\
\hline & & & \\
\hline & & & \\
\hline & & & \\
\hline & & & \\
\hline & & & \\
\hline & & & \\
\hline & & & \\
\hline & & & \\
\hline & & & \\
\hline & & & \\
\hline & & & \\
\hline & & & \\
\hline & & & \\
\hline & & & \\
\hline & & & \\
\hline & & & \\
\hline & & & \\
\hline & & & \\
\hline & & & \\
\hline & & & \\
\hline & & & \\
\hline & & & \\
\hline
\end{tabular}




\begin{tabular}{|c|c|c|c|}
\hline Time & $\begin{array}{c}\text { Food/Drink } \\
\text { Type of food, brand name, } \\
\text { restaurant }\end{array}$ & $\begin{array}{l}\text { Method of Preparation } \\
\text { Description, product } \\
\text { label or recipe }\end{array}$ & $\begin{array}{c}\text { Amount } \\
\text { Tsp, tbsp, } \\
\text { cup, oz, } \\
\text { weight or } \\
\text { portion }\end{array}$ \\
\hline & & & \\
\hline & & & \\
\hline & & & \\
\hline & & & \\
\hline & & & \\
\hline & & & \\
\hline & & & \\
\hline & & & \\
\hline & & & \\
\hline & & & \\
\hline & & & \\
\hline & & & \\
\hline & & & \\
\hline & & & \\
\hline & & & \\
\hline & & & \\
\hline & & & \\
\hline & & & \\
\hline & & & \\
\hline & & & \\
\hline & & & \\
\hline & & & \\
\hline & & & \\
\hline
\end{tabular}


Fish and Your Heart

Daily Food Record

Day 7 - Pre-Study

Name:

Date:

Day of the Week: SUN MON TUES WED THUR FRI SAT

\begin{tabular}{|c|c|c|c|}
\hline Time & $\begin{array}{c}\text { Food/Drink } \\
\text { Type of food, brand name, } \\
\text { restaurant }\end{array}$ & $\begin{array}{l}\text { Method of Preparation } \\
\text { Description, product } \\
\text { label or recipe }\end{array}$ & $\begin{array}{l}\text { Amount } \\
\text { Tsp, tbsp, } \\
\text { cup, oz, } \\
\text { weight or } \\
\text { portion }\end{array}$ \\
\hline & & & \\
\hline & & & \\
\hline & & & \\
\hline & & & \\
\hline & & & \\
\hline & & & \\
\hline & & & \\
\hline & & & \\
\hline & & & \\
\hline & & & \\
\hline & & & \\
\hline & & & \\
\hline & & & \\
\hline & & & \\
\hline & & & \\
\hline & & & \\
\hline & & & \\
\hline & & & \\
\hline & & & \\
\hline & & & \\
\hline & & & \\
\hline & & & \\
\hline & & & \\
\hline
\end{tabular}




\begin{tabular}{|c|c|c|c|}
\hline Time & $\begin{array}{c}\text { Food/Drink } \\
\text { Type of food, brand name, } \\
\text { restaurant }\end{array}$ & $\begin{array}{l}\text { Method of Preparation } \\
\text { Description, product } \\
\text { label or recipe }\end{array}$ & $\begin{array}{l}\text { Amount } \\
\text { Tsp, tbsp, } \\
\text { cup, oz, } \\
\text { weight or } \\
\text { portion }\end{array}$ \\
\hline & & & \\
\hline & & & \\
\hline & & & \\
\hline & & & \\
\hline & & & \\
\hline & & & \\
\hline & & & \\
\hline & & & \\
\hline & & & \\
\hline & & & \\
\hline & & & \\
\hline & & & \\
\hline & & & \\
\hline & & & \\
\hline & & & \\
\hline & & & \\
\hline & & & \\
\hline & & & \\
\hline & & & \\
\hline & & & \\
\hline & & & \\
\hline & & & \\
\hline & & & \\
\hline
\end{tabular}


FISH and HEART DISEASE STUDY

Baseline Survey

Name:

Today's Date:

ID\#:

We'd like to get some information about you and your health habits to help us understand the results of this study. Please complete the following items by clearly writing or circling your answer.

\section{Demographics}

1. How old were you on your last birthday? years

2. Circle your marital status.
a- Single
b- Married
c- Divorced
d- Widowed

3. Circle the highest education level you finished.
a- Grade school or less
b- High school or GED
c- Some college
d- College
e- Graduate degree

4. Circle which best describes your race.
a- White (nonHispanic)
b- African American (nonHispanic)
c- Hispanic
d- Asian
e- Native American

\section{Health Conditions}

5. Circle the method of menopause you experienced.
a- natural
b- surgical (complete hysterectomy)
c- other: please describe

6. What was the month and year of your last period? (month) (year)

7. Did either of your parents have a heart attack before they were 60 years old? Yes / No

8. What is your height? (feet) (inches)

9. What is your weight? (pounds) 
10. Please list any heart-related conditions you have. Write 'none' if you do not have any.

11. Please list all medications you are currently taking. Write 'none' if you are not taking any.

\section{Lifestyle habits}

12. Circle your smoking status.

a- I smoke occasionally

b- I used to smoke but quit

c- I never smoked

13. Circle how often you usually exercise (sweat and breath heavy for 20 minutes or more).
a- A few times a week
b- Once a week
c- Less than once a week

14. Circle how often you usually have an alcoholic beverage (beer, wine, or hard liquor).
a- Every day
b- A few times a week
c- A few times a month
d- A few times a year
e- I never drink alcohol

15. Circle how often you usually take aspirin. This DOES NOT include Tylenol or ibuprofen.
a- Every day
b- A few times a week
c- A few times a month
d- A few times a year
e- I never use aspirin

16. Circle how often you usually take ibuprofen (trade name Motrin or Rufen).
a- Every day
a- A few times a week
b- A few times a month
c- A few times a year
d- I never use ibuprofen 
17. Please circle all of the following anti-inflammatory medications that you are currently taking or have taken in the past year.

\section{Glucocorticoids}

Hydrocortisone Betamethasone

Cortisone

Dexamethasone

Prednisone

Paramethasone

Prednisolone

Triamcinolone

Methylprednisolone

\section{Nonsteroidal Anti-Inflammatory Drugs (NSAIDS)}

\section{Generic Name}

Magnesium salicylate

Choline salicylate

Choline magnesium trisalicylate

Salsalate

Diclofenac sodium

Diflunisal

Fenoprofen calcium

Flurbiprofen

Indomethacin

Ketoprofen

Meclofenamate sodium

Naproxen

Naproxen sodium

Phenylbutazone

Piroxicam

Sulindac

Tolmetin sodium
Trade Name

Mobidin, Magan

Arthropan liquid

Trilisate

Disalcid

Voltaren

Dolobid

Nalfon

Ansaid

Indocin

Orudis

Meclomen

Naprosyn

Anaprox

Butazolidin

Feldene

Clinoril

Tolectin 


\section{More Quick Meal Ideas}

- Cook fillet in microwave. Flake and add to canned vegetable soup or potato-corn chowder.

- Cook fillet in microwave. Flake and toss with pasta, vegetables and Italian dressing.

- Pan-fry fillet and add to tossed green salad. Serve with crusty bread.

- Pan-fry fillet and serve on a warmed bun with lettuce and tomato.

\section{More Seasoning Suggestions}

- Cook fish plain using any method, then serve with your choice of sauce.
- Barbeque
o Teriyaki
- Cheese
o Salsa
- Marinara
o Mushroom

- Brush fillet with oil, sprinkle on one of the following seasonings, then broil.

- Lemon Pepper

- Old Bay Seasoning

- Italian Seasoning Mix

\section{TROUT RECIPES}

\section{PREPARATION POINTERS}

\section{Baking}

Trout is best baked at a moderately high temperature, 400$450^{\circ} \mathrm{F}$, for a short period of time. Enhance moistness and flavor with seasoned oil. Test for doneness by probing with a fork. If the fish flakes easily, it is done. Do not try to turn the fish during the baking process.

\section{Broiling}

Place the trout no closer than 4 inches to the source of heat. Baste well with an oil or sauce before and during the cooking process to prevent the fish from being too dry.

\section{Grilling}

Place the trout fillet on foil and grill approximately 4-6 inches from the hot charcoal. Cooking time varies with the temperature of the grill. It will require about 3-4 minutes.

\section{Pan-Frying}

Use a small amount of oil. Roll the fish in a coating and fry lightly or sauté at a moderate temperature until browned on one side. Trout is done when the flesh flakes easily with a fork.

\section{Microwave}

Microwave cooking is especially suited to the high temperature and short time required for cooking trout. Always thaw trout completely to ensure an even cooking. Cover the fish with plastic wrap, but turn back one corner to allow venting. Cook fillet at HIGH for $\sim 1$ minute (less for plain fish, more for fish with sauce). Allow the fish to stand 1 minute to complete cooking.

Tip: Overcooking trout dries out and toughens the fish. Trout is done when it flakes easily with a fork.

\section{DO NOT DEEP-FAT FRY THE STUDY FISH}




\section{Baked Parmesan Trout}

1 Tbsp grated Parmesan cheese

2 Tbsp toasted breadcrumbs

1 Tbsp skim milk

1 dash hot pepper sauce

1 dash pepper

1 dash paprika

Preheat oven to $400^{\circ} \mathrm{F}$. Combine Parmesan cheese, bread crumbs, pepper and paprika. In another bowl, combine milk and hot sauce. Dip fillet in milk mixture. Coat with breadcrumb mixture. Place fish on baking dish. Bake 10 minutes or until golden brown.

\section{Cajun Baked Trout}

1 Tbsp Cajun seasoning

1 Tbsp water

1 trout fillet

Preheat oven to 400 degrees. Mix the water and seasoning together; brush onto the trout fillet and bake on a pan sprayed with nonstick spray. Bake about 10 minutes or until done. More seasoning can be added if you like a spicier taste.

\section{Lemon Broiled Trout}

1 trout fillet

1 dash paprika

1 tsp oil

1 Tbsp lemon juice

1 dash salt

Brush fish with oil and place on baking pan. Sprinkle with salt and paprika. Broil 4 inches from the heat for 2 minutes. Remove and pour lemon juice over fish. Broil another 2 minutes.

\section{Zippy Broiled Trout}

1 trout fillet

1 Tbsp bottled Italian salad dressing

Dip fish in dressing and place on baking pan. Broil 4 inches from heat for 4 minutes.

\section{Basic Pan-Fried Trout}

1 trout fillet $\quad 1$ Tbsp flour

1 Tbsp milk oil for pan-fry

Dip fillet in milk then dredge in flour. Pan-fry in small amount of oil. Serve with lemon wedges or your choice of sauce.

\section{Breaded Pan-Fried Trout}
1 trout fillet
oil for pan-fry
1 Tbsp milk
$1 / 2$ cup marinara sauce (optional)

2 Tbsp seasoned breadcrumbs

Dip fillet in milk. Coat with breadcrumbs. Pan-fry in oil. Serve with marinara sauce.

\section{Microwave Teriyaki Trout}

2 tsp soy sauce $\quad 1 / 2$ small clove garlic, minced

$1 / 4$ tsp sugar $\quad 1$ trout fillet

$1 / 4$ tsp ground ginger

In small bowl, combine soy sauce, sugar, ginger and garlic. Place fish in microwave-safe dish. Pour sauce over fish. Cover and microwave 2 minutes on high or until trout flakes easily.

\section{Trout Salad Sandwich}

\section{1 trout fillet \\ $1 / 2$ stalk celery, chopped \\ 1 Tbsp lite mayonnaise 2 slices bread or pita pocket}

Place fillet in microwave-safe dish. Cover loosely. Cook on HIGH $~ 45$ seconds or until done. Cool. Flake fish and mix with mayonnaise and celery. Serve on bread with your choice of fixings. 


\section{WVU FISH STUDY}

Contents: 16 uncooked fillets rainbow trout.

For consumption by study participants only.

\section{KEEP FISH FROZEN UNTIL READY TO USE. See reverse side for handling instructions.}

The Fish Study is being conducted by

WVU College of Agriculture

Division of Animal and Nutritional Sciences

Direct questions regarding the fish to Cindy Fitch 304-293-2631 ext 4415

\section{SAFE FISH HANDLING INSTRUCTIONS}

\section{THAWING}

Never defrost on counter top or in warm water. Use one of the following methods.

Do not refreeze uncooked fish.

Refrigerator Place unopened fillet bag in refrigerator and let thaw overnight.

Cold water Place unopened fillet bag in pan of cold water and change water every 30 minutes. Or thaw in unopened bag under cold running water.

Microwave Cut bag open and place bag of fish in microwave-safe dish. Thaw on defrost setting for 2-3 minutes. Fish must be cooked immediately following microwave defrosting.

\section{PREPARATION}

Always wash hands thoroughly with hot, soapy water before preparing foods and after handling raw fish. Don't let raw fish or juices touch ready-to-go foods either in the refrigerator or during preparation. Don't put cooked foods on the same plate that held raw fish. Always wash utensils that have touched raw fish with hot, soapy water before using them for cooked foods. Wash counters, cutting boards and other surfaces raw fish have touched.

\section{COOKING}

Cook the fish until it begins to flake and loses its translucent or raw appearance. 


\section{INTERNATIONAL PHYSICAL ACTIVITY QUESTIONNAIRE}

We are interested in finding out about the kinds of physical activities that people do as part of their everyday lives. The questions will ask you about the time you spent being physically active in the last 7 days. Please answer each question even if you do not consider yourself to be an active person. Please think about the activities you do at work, as part of your house and yard work, to get from place to place, and in your spare time for recreation, exercise or sport.

Think about all the vigorous activities that you did in the last 7 days. Vigorous physical activities refer to activities that take hard physical effort and make you breathe much harder than normal. Think only about those physical activities that you did for at least 10 minutes at a time.

1. During the last $\mathbf{7}$ days, on how many days did you do vigorous physical activities like heavy lifting, digging, aerobics, or fast bicycling? days per week

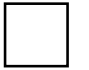

No vigorous physical activities Skip to question 3

2. How much time did you usually spend doing vigorous physical activities on one of those days?

hours per day minutes per day

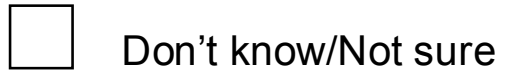

Think about all the moderate activities that you did in the last 7 days. Moderate activities refer to activities that take moderate physical effort and make you breathe somewhat harder than normal. Think only about those physical activities that you did for at least 10 minutes at a time.

3. During the last 7 days, on how many days did you do moderate physical activities like carrying light loads, bicycling at a regular pace, or doubles tennis? Do not include walking.

days per week

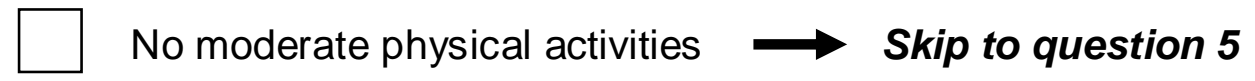


4. How much time did you usually spend doing moderate physical activities on one of those days?

hours per day minutes per day

$\square$ Don't know/Not sure

Think about the time you spent walking in the last $\mathbf{7}$ days. This includes at work and at home, walking to travel from place to place, and any other walking that you might do solely for recreation, sport, exercise, or leisure.

5. During the last $\mathbf{7}$ days, on how many days did you walk for at least 10 minutes at a time?

days per week

$\square$ No walking $\longrightarrow$ Skip to question 7

6. How much time did you usually spend walking on one of those days?

hours per day minutes per day

$\square$ Don't know/Not sure

The last question is about the time you spent sitting on weekdays during the last 7 days. Include time spent at work, at home, while doing course work and during leisure time. This may include time spent sitting at a desk, visiting friends, reading, or sitting or lying down to watch television.

7. During the last $\mathbf{7}$ days, how much time did you spend sitting on a week day?

hours per day minutes per day

Don't know/Not sure

This is the end of the questionnaire, thank you for participating. 


\section{WWestVirginiaUniversity.}

Office of Research Compliance

CONSENT AND INFORMATION FORM

OMR ICF

Principal Investigator: Fitch, Cindy

Department:

AGRICULTURE \& FORESTRY - Animal/Vet. Science

Tracking Number: $\quad \mathrm{H}-20810$

Study Title:

The Effects of Omega-3 Enriched Trout on C-Reactive Protein

Concentrations

Co-Investigator(s):

Fitch, Cindy, Moran, Megan

Sponsor

US Department of Agriculture

Contact Persons

If you have any questions, concerns, or complaints about this research, you can contact Dr. Cindy Fitch at 304/293-2631, extension 4415

For information regarding your rights as a research subject, you may contact the Office of Research Compliance at 304/293-7073.

Introduction

You, , have been asked to participate in this research study, which has been explained to you by . This study is being conducted by Cindy Fitch, Ph.D., RD in the Department of Human Nutrition and Foods at West Virginia University with funding provided by the US Department of Agriculture.

Purposes of the Study

\begin{tabular}{lllll}
\hline Tracking \#: & $\mathrm{H}-20810$ & Page 1 of 5 & \\
Approved On: & $05 / 07 / 2008$ & & & Initials \\
Valid Through: & $05 / 06 / 2009$ & & & \\
Last Amended: & N/A & & &
\end{tabular}


The purpose of this study is to learn more about diet and heart health. WVU expects to enroll approximately 60 subjects; a total of approximately 60 subjects at all sites are expected to participate in this study.

\section{Description of Procedures}

This study involves attending an informational meeting at the beginning and end of the study and will take approximately 1 hour. You will be asked to fill out a questionnaire regarding your health history. This will take approximately 30 minutes. You do not have to answer all the questions. You will have the opportunity to see the questionnaire before signing this consent form. You will also be asked to keep track of everything that you eat or drink for 7 days at the beginning and end of the study and to participate in 2 phone calls with a registered dietitian. Each phone call will last about 30 minutes and you will be asked questions about the food you ate. You do not need to answer any question that make you feel uncomfortable. You will be asked to go to a local Lab Corp clinic to have blood drawn at the beginning and end of the study. You will be provided with directions to the nearest Lab Corp facility and their business hours. You may go anytime within the first week of the study that is convenient to you. You will need to arrange your own transportation. About 1 tablespoon will be drawn from a vein in your arm each time for a total of 2 tablespoons during the study. The total amount of blood withdrawn during the study will be about one-fifteenth (1/15) of what is taken for a standard blood donation. There will be no cost to you for the blood draw. The following laboratory values will be measured in the blood; $\mathrm{C}$-reactive protein, interleukin 6, total, LDL- and HDL-cholesterol, and triglycerides. You will be randomly assigned (like flipping a coin) to a study group. If you are assigned to the control group, you will eat your usual diet for the 8-week study. If you are assigned to the fish group, you will be asked to eat omega-3-enriched fish twice a week for 8 weeks. The fish will be provided free and you will need to pick them up at the designated time and place.

Risks and Discomforts

Having blood drawn may cause bruising, bleeding, or in rare cases, infection. The fish will be grown and processed in West Virginia University

\begin{tabular}{lll}
\hline Tracking \#: & H-20810 & Page 2 of 5 \\
Approved On: & $05 / 07 / 2008$ & \\
Valid Through: & $05 / 06 / 2009$ & \\
Last Amended: & N/A &
\end{tabular}


facilities where they will be monitored and tested for safety. There are no expected risks or side effects from eating the fish.

\section{Alternatives}

You do not have to participate in this study.

Alternatives that could be considered in your case include not participating in the study.

\section{Benefits}

You may not receive any direct benefit from this study. The knowledge gained from this study may eventually benefit others.

Financial Considerations

There are no special fees for participating in this study. The fish will be provided free to those who are randomly assigned to the fish group. The cost of the lab tests will be paid by the study and neither you nor your insurance company will be charged.

Confidentiality

Any information about you that is obtained as a result of your participation in this research will be kept as confidential as legally possible. Your research records and test results, just like hospital records, may be subpoenaed by court order or may be inspected by federal regulatory authorities without your additional consent. A special number will be used to identify you in the study and only the investigators will know your name. In any publications that result from this research, neither your name nor any information from which you might be identified will be published without your consent.

Voluntary Participation

Participation in this study is voluntary. You are free to withdraw your consent to participate in this study at any time. Refusal to participate or withdrawal will not affect your future care and will involve no penalty to you. In the event new information becomes available that may affect your willingness to participate in this study, this information will be given to you

\begin{tabular}{lllll}
\hline Tracking \#: & $\mathrm{H}-20810$ & Page 3 of 5 & & \\
Approved On: & $05 / 07 / 2008$ & & & Date \\
Valid Through: & $05 / 06 / 2009$ & & & \\
Last Amended: & N/A & & &
\end{tabular}


so that you can make an informed decision about whether or not to continue your participation. You have been given the opportunity to ask questions about the research, and you have received answers concerning areas you did not understand.

$\begin{array}{lll}\text { Tracking \#: } & \mathrm{H}-20810 & \text { Page } 4 \text { of } 5 \\ \text { Approved On: } & 05 / 07 / 2008 & \\ \text { Valid Through: } & 05 / 06 / 2009 & \\ \text { Last Amended: } & \text { N/A } & \end{array}$


Upon signing this form, you will receive a copy.

I willingly consent to participate in this research.

\begin{tabular}{llll}
\hline $\begin{array}{l}\text { Signature of Subject or } \\
\text { Subjects Legal Representative }\end{array}$ & Date & & Timed Name
\end{tabular}

The participant has had the opportunity to have questions addressed. The participant willingly agrees to be in the study.

Signature of Investigator or

Printed Name

Date

Time

Co-Investigator

$\begin{array}{lll}\text { Tracking \#: } & \mathrm{H}-20810 & \text { Page } 5 \text { of } 5 \\ \text { Approved On: } & \text { 05/07/2008 } & \\ \text { Valid Through: } & 05 / 06 / 2009 & \\ \text { Last Amended: } & \text { N/A } & \end{array}$

$\overline{\text { Initials }} \overline{\text { Date }}$




\section{W. WestVirginiaUniversity.}

Office of Research Compliance

Effects of Omega-3 Enriched Fish Consumption on C-Reactive Protein in PostMenopausal Women

Principal Investigator: Fitch, Cindy

Department:

Tracking Number: $\quad \mathrm{H}-20810$

Study Title:

The Effects of Omega-3 Enriched Trout on C-Reactive Protein

Concentrations

Co-Investigator(s):

Fitch, Cindy, Moran, Megan

Sponsor

West Virginia University Aquaculture Research and Marketing Project

Subject's Name:

ID

Number:

We know that information about you and your health is private. We are dedicated to protecting the privacy of that information. Because of this promise, we must get your written authorization (permission) before we may use or disclose your protected health information or share it with others for research purposes. This form gives that permission. It also helps us make sure that you are correctly told how this information will be used or disclosed. Please read the information below carefully before signing this form. Please ask any questions you may have about this form or its uses. You can decide to sign or not to sign this authorization form. However, if you choose not to sign this authorization form, you will not be able to take part in the research study. Whatever choice you make about this research study, it will not have an effect on your access to medical care.

USE AND DISCLOSURE COVERED BY THIS AUTHORIZATION

DO NOT SIGN A BLANK FORM. You or your authorized representative

\begin{tabular}{lll}
\hline Tracking \#: & H-20810 & Page 1 of 4 \\
Approved On: & 05/07/2008 & \\
Valid Through: & $05 / 06 / 2009$ & \\
Last Amended: & N/A
\end{tabular}


should thoroughly read the information below before signing this form. Who will disclose, receive, and/or use the information? This form will authorize the following person(s), class(es) of persons, and/or organization (s) to disclose, use, and receive the information*:

Study investigators, clinical coordinator, laboratory personnel;

The research site(s) carrying out this study (WVU and LabCorp). It also includes each site's research staff and medical staff.

Health care providers who provide services to you as part of this research study.

Laboratories and other people and groups that look into your health information as part of this study in agreement with the study protocol. The United States Department of Health and Human Services (which includes the National Institutes of Health, Food and Drug Administration (FDA) and other groups that have the right to use the information as required by law.

* If, during the course of the research, one of the companies or institutions listed above merges with, or is purchased by, another company or institution, this authorization to use or disclose protected health information in the research will extend to the successorcompany or institution.

What information will be used or disclosed?

Information that will be used for the purposes of the study include answers to survey questions, dietary intake data, and results of laboratory tests, (C-reactive protein, interleukin 6, total, LDL- and HDL-cholesterol, and triglycerides).

\section{SPECIFIC UNDERSTANDINGS}

By signing this research authorization form, you give permission for the use and/or disclosure of your protected health information described above. The purpose for the uses and disclosures you are authorizing is to carry out the research study explained to you during the informed consent process. It is also to ensure that the information relating to the research is available to all parties who may need it for research purposes. Your protected health information may be used as necessary for your researchrelated treatment or to collect payment for your research-related treatment (when applicable). It may also be used to run the business operations of the institution.

This information may be redisclosed or used for other purposes if a

\begin{tabular}{lll}
\hline Tracking \#: & $\mathrm{H}-20810$ & Page 2 of 4 \\
Approved On: & $05 / 07 / 2008$ & \\
Valid Through: & $05 / 06 / 2009$ & \\
Last Amended: & N/A
\end{tabular}


recipient described in this form is not required by law to protect the privacy of the information.

You have a right to refuse to sign this authorization. Your health care outside the study, the payment for your health care, and your health care benefits will NOT be affected if you do not sign this form. However you will NOT be able to take part in the research study described in this authorization if you do not sign this form.

If you sign this authorization, you will have the right to cancel it at any time, except to the extent that WVU Division of Animal and Nutritional Sciences has already taken action based upon your authorization or needs the information to complete analysis and reports of data for this research study. To cancel this authorization, please write to the Principal Investigator, Cindy Fitch, Ph.D., RD at: Mailbox \#:6108, Morgantown, WV 26506-6108.

You will be allowed to see or copy the information described on this form as long as the research is in progress, but you have a right to see and copy the information upon completion of the research in accordance with hospital policies.

The members and staff of any Institutional Review Board (IRB) that oversees this research study.

The Principal Investigator: Dr. Cindy Fitch

Members of WVU, Division of Animal and Nutritional

Sciences administrative staff responsible for administering clinical trials and other research activities, including the Clinical Trials, Office/Office of Research and Sponsored Programs.

You have a right to receive a copy of this form after you have signed it.

Expiration Date:

THE SUBJECT OR HIS/HER AUTHORIZED REPRESENTATIVE MUST BE PROVIDED WITH A COPY OF THIS FORM AFTER IT HAS BEEN SIGNED.

\section{SIGNATURE}

I have read this form and all of my questions about this form have been answered. By signing below, I acknowledge that I have read and accept all of the above.

\begin{tabular}{lll}
\hline Tracking \#: & $\mathrm{H}-20810$ & Page 3 of 4 \\
Approved On: & $05 / 07 / 2008$ & \\
Valid Through: & $05 / 06 / 2009$ & \\
Last Amended: & N/A
\end{tabular}


Signature of Subject or Authorized Representative Date

Print Name of Subject or Authorized Representative

Relationship of the person signing as Subject or Authorized Representative above to the Subject

Print Name of Individual Explaining this Research Authorization Form

\section{CONTACT INFORMATION}

The contact information of the subject or authorized representative who signed this form should be filled in below.

Address:

Telephone:

(daytime)

(evening)

E-mail Address (optional):

Tracking \#:

Approved On:

Valid Through:

Last Amended:
$\mathrm{H}-20810$

05/07/2008

05/06/2009

N/A
Page 4 of 4

$\overline{\text { Initials }} \overline{\text { Date }}$ 
FISH and HEART DISEASE STUDY

Post Survey

Name:

Today's Date:

ID\#:

\section{Changes during the Study}

We want to know if certain things changed for you during the study.

Please circle whether or not the following happened DURING THE 12-WEEK STUDY.

1. I was diagnosed with diabetes. $\quad$ Yes No

2. I was diagnosed with high blood pressure (hypertension). $\quad$ Yes No

3. I was diagnosed with heart disease (such as angina, congestive heart $\quad$ Yes No failure, peripheral arterial disease).

If yes, please describe:

4. I had a heart attack. $\quad$ Yes No

5. I had a major injury (such as a broken bone or severe burn). $\quad$ Yes $\quad$ No If yes, please describe:

6. I had surgery. $\quad$ Yes No

7. I gained more than 5 pounds. $\quad$ Yes No

8. I lost more than 5 pounds. $\quad$ Yes No

9. Please mark $(\mathrm{X})$ which changes you made to follow a heart healthy diet for this study.

Reduced amount of commercial salad dressing I used.

Reduced amount of margarine I used.

Reduced amount of mayonnaise I used.

Reduced amount of full-fat dairy products I ate. 


\section{Satisfaction with the Study Experience}

We want to know your thoughts about eating the fish and being a part of the study.

On a scale of 1-5 please rate the following items.

10. I liked the taste of the fish provided by the study. Strongly Strongly

11. It was convenient getting the fish for the study.

12. It was easy to prepare the fish for meals.

13. It was hard trying to eat the fish twice a week.

14. I may try to keep eating fish twice a week.

15. I learned new ways to eat heart healthy.

16. The heart healthy diet had too many changes.

17. I want to keep eating a heart healthy diet.

Agree

$\begin{array}{lllll}1 & 2 & 3 & 4 & 5 \\ 1 & 2 & 3 & 4 & 5 \\ 1 & 2 & 3 & 4 & 5 \\ 1 & 2 & 3 & 4 & 5 \\ 1 & 2 & 3 & 4 & 5 \\ 1 & 2 & 3 & 4 & 5 \\ 1 & 2 & 3 & 4 & 5 \\ 1 & 2 & 3 & 4 & 5\end{array}$

18. How could we make it easier to eat the fish twice a week in future studies?

19. What did you like the least about being in the study?

20. What did you like the most about being in the study?

Thank you for being part of this study. Your contribution may help the health of other women. 


\section{Thanks for participating in the study!}

Tonight you will be receiving your blood work results and nutrition analysis. If you have questions or concerns about any of the results, please contact your physician.

To help you understand where your diet may need changes, the following recommendations were published in the 2005 Dietary Guidelines for Americans:

- Carbohydrates should be between 45 and $65 \%$ of the total calories consumed

- Total fats should be between 20 and $35 \%$ of the total calories consumed

- Saturated fats should be limited to less than $10 \%$ of your total calories

- Protein should be between 10 and $35 \%$ of total calories consumed

- Sodium intake should be less than $2300 \mathrm{mg}$ per day

- Fiber intake should be approximately 14 grams per every 1,000 calories

The following table shows calorie guidelines from the American Heart Association:

$\begin{array}{ccccc}\text { Gender } & \begin{array}{c}\text { Age } \\ \text { Agears) }\end{array} & \text { Sedentary' } & \text { Moderately Active } & \text { Active }^{s} \\ \text { Female } & 19-30 & 2,000 & 2,000-2,200 & 2,400 \\ & 31-50 & 1,800 & 2,000 & 2,200 \\ & 51+ & 1,600 & 1,800 & 2,000-2,200\end{array}$

\section{Ranges for CRP levels are as follows:}

Low - less than 1

Average - 1 to 3

High - greater than 3

The following tables are from the American Heart Association and give the ranges for cholesterol and triglycerides.

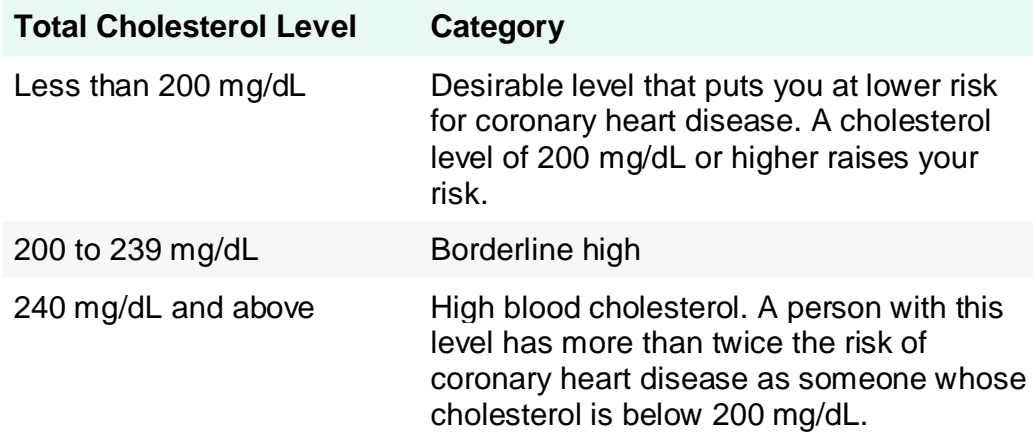

High blood cholesterol. A person with this level has more than twice the risk of coronary heart disease as someone whose cholesterol is below $200 \mathrm{mg} / \mathrm{dL}$. 
HDL Cholesterol Level

Less than $40 \mathrm{mg} / \mathrm{dL}$

(for men)

Less than $50 \mathrm{mg} / \mathrm{dL}$

(for women)

$60 \mathrm{mg} / \mathrm{dL}$ and above
Category

Low HDL cholesterol. A major risk factor for heart disease.

High HDL cholesterol. An HDL of 60 $\mathrm{mg} / \mathrm{dL}$ and above is considered protective against heart disease.
LDL Cholesterol Level

Less than $100 \mathrm{mg} / \mathrm{dL}$

100 to $129 \mathrm{mg} / \mathrm{dL}$

130 to $159 \mathrm{mg} / \mathrm{dL}$

160 to $189 \mathrm{mg} / \mathrm{dL}$

$190 \mathrm{mg} / \mathrm{dL}$ and above

Triglyceride Level

Less than $150 \mathrm{mg} / \mathrm{dL}$

150-199 mg/dL

200-499 mg/dL

$500 \mathrm{mg} / \mathrm{dL}$ and above

\section{Category}

Optimal

Near or above optimal

Borderline high

High

Very high

For more information, visit:

http://www.americanheart.org http://www.eatright.org

http://www.americanheart.org/presenter.jhtml?identifier=4500

http://www.health.gov/DietaryGuidelines/dga2005/document/default.htm

http://www.americanheart.org/presenter.jhtml?identifier=3055399

http://www.americanheart.org/presenter.jhtml?identifier $=3055398$

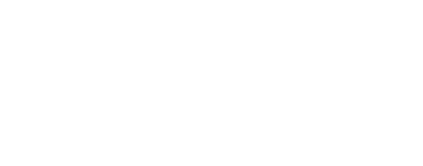

